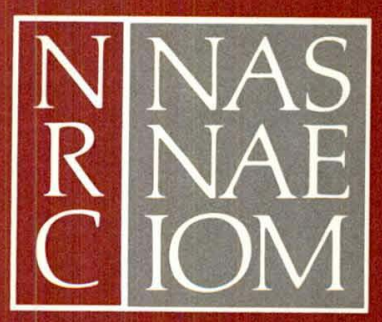

NASA-CR-172960 19830024944

$A D-A 132,370$

\title{
Fracture in Compression of Brittle Solids
}

LIBnARY GOPY

ip ? 1983

LENGLEY RESEARCH CENTER

LIBRARY, NASA

HAMPTON, VIRGINIA

National Materials Advisory Board

Commission on Engineering and Technical Systems

National Research Council

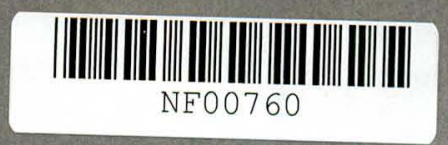




\section{NATIONAL RESEARCH COUNCIL \\ COMMISSION ON ENGINEERING AND TECHNICAL SYSTEMS}

\section{NATIONAL MATERIALS ADVISORY BOARD}

The purpose of the National Materials Advisory Board is the advancement of materials science and engineering in the national interest.

\section{CHAIRMAN}

Dr. Donald J. McPherson (Retired)

Kaiser Aluminum \& Chemical Corporation 1180 Monticello Road

Lafayette, CA 94549

\section{PAST CHAIRMAN}

Mr. William D. Manly

Senior Vice President

Cabot Corporation

125 High Street

Boston, MA 02110

\section{Members}

Dr. Arden L. Bement, Jr.

Vice President, Technology Resources

Science and Technical Department

TRW, Inc.

23555 Euclid Ave.

Cleveland, $\mathrm{OH} 44117$

Dr. William J. Burlant

Director, Lexington Laboratory

The Kendall Co.

Lexington, MA 02173

Dr. James C. Burrows

Vice President

Charles River Associates

200 Clarendon Street

John Hancock Tower, 43rd Floor

Boston, MA 02116

Dr. Raymond F. Decker

Vice President, Research

Michigan Technological University

Houghton, MI 49931

Mr. Edward J. Dulis

President

Crucible Research Center

Colt Industries

P.O. Box 88

Pittsburgh, PA 15230

Dr. Brian R. T. Frost

Division Director, Materials Science

Argonne National Laboratory

9700 South Cass Avenue

Argonne, IL 60439

Dr. Serge Gratch

Director of Chemistry Science Lab

Engineering \& Research Staff

Ford Motor Co.

P.O. Box 2053

Dearborn, MI 48121
Dr. Nick Holonyak, Jr.

Professor Electronic Engineering

University of Illinois-Urbana

Dept. of Electrical Engineering

Urbana, IL 61801

Dr. Paul J. Jorgensen

Vice President, SRI International

333 Ravenswood Avenue

Menlo Park, CA 94025

Dr. Alan Lawley

Professor Metallurgical Engineering

Drexel University

Department of Materials Engineering

Philadelphia, PA 19104

Dr. Raymond F. Mikesell

W. E. Miner Professor of Economics

University of Oregon

Department of Economics

Eugene, OR 97403

Dr. David L. Morrison

President

IIT Research Institute

10 West 35th Street

Chicago, IL 60616

Dr. David Okrent

Professor of Engineering \& Applied Science

University of California, Los Angeles

5532 Boelter Hill

Los Angeles, CA 90024

Dr. R. Byron Pipes

Director, Center for

Composite Materials

Department of Mechanical \&

Aerospace Engineering

University of Delaware

Newark, DE 19711
Professor James R. Rice

Gordon McKay Professor of

Engineering Sciences and Geophysics

Division of Applied Sciences

Harvard University

Peirce Hall

Cambridge, MA 02138

Dr. Brian M. Rushton

Vice President, Research \& Development

Air Products \& Chemicals, Inc.

P.O. Box 538

Allentown, PA 18105

Dr. William P. Slichter

Executive Director, Research

Materials Science and Engineering Division

Bell Laboratories

600 Mountain Avenue

Murray Hill, NJ 07974

Dr. William A. Vogely

Professor and Head

Department of Mineral Economics

Pennsylvania State University

University Park, PA 16802

Dr. Robert P. Wei

Department of Mechanical Engineering and Mechanics

Lehigh University

Bethlehem, PA 18015

Dr. Albert R.C. Westwood

Director, Martin Marietta Labs

Martin Marietta Corporation

1450 South Rolling Road

Baltimore, MD 21227

\section{NMAB STAFF}

K.M. Zwilsky, Executive Director 


\begin{tabular}{|c|c|}
\hline REPORT DOCUMENTATION PAGE & $\begin{array}{l}\text { READ INSTRUCTIONS } \\
\text { BEFORE COMPLETING FORM }\end{array}$ \\
\hline \begin{tabular}{l|l|} 
1. REPORT NUMBER & 2. GOVT ACCESSION NO. \\
NMAB -404 &
\end{tabular} & 3. RECIPIENT'S CATALOG NUMBER \\
\hline \multirow[t]{2}{*}{$\begin{array}{l}\text { 4. TITLE (and Subtillo) } \\
\text { Fracture in Compression of Brittle Solids }\end{array}$} & $\begin{array}{l}\text { 5. TYPE OF REPORT Q PERIOD COVERED } \\
\text { Final RepOTt }\end{array}$ \\
\hline & $\begin{array}{l}\text { 6. PERFORMING ORG. REPORT NUMBER } \\
\text { NMAB }-404\end{array}$ \\
\hline $\begin{array}{l}\text { 7. AUTHOR(o) } \\
\text { Committee on Fracture in Compressive Stress Fields }\end{array}$ & $\begin{array}{l}\text { 8. CONTRACT OR GRANT NUMBER(०) } \\
\text { MDA } 903-82-C-0434\end{array}$ \\
\hline $\begin{array}{l}\text { 9. PERFORMING ORGANIZATION NAME AND ADORESS } \\
\text { National Materials Advisory Board } \\
\text { National Academy of Sciences } \\
\text { 2101 Constitution Ave N.W. } \\
\text { Washington, D.C. 204i8 }\end{array}$ & $\begin{array}{l}\text { 10. PROGRAM ELEMENT'PROJECT, TASK } \\
\text { AREA \& WORK UNIT'NUMBERS }\end{array}$ \\
\hline 11. CONTROLLING OFFICE NAME AND ADDRESS & $\begin{array}{l}\text { 12. REPORT OATE } \\
\text { August } 1983\end{array}$ \\
\hline & $\begin{array}{l}\text { 13. NUMBER OF PAGES } \\
70\end{array}$ \\
\hline 14. MONITORING AGENCY NAME \& ADORESS(Il different from Controlline Olfice) & 15. SECURITY CLASS. (ol thie soport) \\
\hline $\begin{array}{l}\text { Defense Advanced Research Projects Agency } \\
\text { Department of Defense/National Aeronautics and }\end{array}$ & Unclassified \\
\hline $\begin{array}{l}\text { Space Administration } \\
\text { Washington, D.C. }\end{array}$ & $\begin{array}{l}\text { 15. DECLASSTFICATION/DOWNGRADING } \\
\text { SCHEDULE }\end{array}$ \\
\hline
\end{tabular}

16. DISTRIBUTION STATEMENT (Ot thte Roport)

This report is for sale by the Defense Technical Information Center, Cameron Station, Alexandria, Virginia 22312.

17. DISTRIBUTION STATEMENT (of the abetract ontered in Block 20, If dilferent from Report)

18. SUPPLEMENTARY NOTES

19. KEY WOROS (Continue on reverae aide II noceseary and identfly by block number)

Acoustic Emission High Strength Steel

Compression

Copperhead

Nondestructive Evaluation

Cracking

Rock Fracture

Fracture

20. ABSTRACT (Continue on reverae olde If neceneary and ldontlty by block number)

The fracture of brittle solids in monotonic compression is reviewed from both the mechanistic and phenomenological points of view. The fundamental theoretical developments based on the extension of pre-existing cracks in general multi-axial stress fields are recognized as explaining extrinsic behavior where a single crack is responsible for the final failure. In contrast, shear faulting in compression is recognized to be the result of an evolutionary localization process involving en echelon action of cracks and 
is termed intrinsic. The mechanistic models are related to the phenomenological developments in dilatational plasticity that have been applied widely in concrete technology. The state of understanding of fracture in compression in rocks, concrete, cemented carbides, ultra-high-strength steels, and fiber-reinforced composites is reviewed in some detail, both from the point of view of fundamentals as well as technological applications. Experimental verification of models is discussed, and possibilities for nondestructive detection of extrinsic flaws and for monitoring damage evolution by acoustic emission are enumerated and evaluated. 
FRACTURE IN COMPRESSION OF BRITTLE SOLIDS

\author{
Report of the \\ Committee on Fracture in Compressive Stress Fields
}

NATIONAL MATERIALS ADVISORY BOARD

Commission on Engineering and Technical Systems

National Research Council

NMAB -404

NATIONAL ACADEMY PRESS

Washington, D.C.

1983 
NOTICE: The project that is the subject of this report was approved by the Governing Board of the National Research Council, whose members are drawn from the Councils of the National Academy of Sciences, the National Academy of Engineering, and the Institute of Medicine. The members of the panel responsible for the report. were chosen for their special competences and with regard for appropriate balance.

The report has been reviewed by a group other than the authors according to procedures approved by a Report Keview Committee consisting of members of the National Academy of Sciences, the National Academy of Engineering, and the Institute of Medicine.

The National Research Council was established by the National Academy of Sciences in 1916 to associate the broad community of science and technology with the Academy's purposes of furthering knowledge and of advising the federal government. The Council operates in accordance with general policies determined by the Academy under the authority of it.s congressional charter of 1863, which established the Academy as a private, nonprofit, self-governing membership corporation. The Council has become the principal operating agency of both the National Academy of Sciences and the National Academy of Engineering in the conduct of their services to the government, the public, and the scientific and engineering communities. It is administered jointly by both Academies and the Institute of Medicine. The National Academy of Engineering and the Institute of Medicine were established in 1964 and 1970, respectively, under the charter of the National Academy of Sciences.

This study by the National Materials Advisory Board was conducted under Contract No. MWA 903-82-C-0434 with the Department of Defense and the National Aeronautics and Space Administration.

This report is for sale by the Defense Technical Information Center, Cameron Station, Alexandria, Virginia 22312.

Printed in the United States of America. 


\section{ABSTRACT}

The fracture of brittle solids in monotonic compression is reviewed from both the mechanistic and phenomenological points of view. The fundamental theoretical developments based on the extension of pre-existing cracks in general multi-axial stress fields are recognized as explaining extrinsic behavior where a single crack is responsible for the final failure. In contrast, shear faulting in compression is recognized to be the result of an evolutionary localization process involving en echelon action of cracks and is termed intrinsic. The mechanistic models are related to the phenomenological developments in dilatational plasticity that have been applied widely in concrete technology. The state of understanding of fracture in compression in rocks, concrete, cemented carbides, ultra-high-strength steels, and fiber-reinforced composites is reviewed in some detail, both from the point of view of fundamentals as well as technological applications. Experimental verification of models is discussed, and possibilities for nondestructive detection of extrinsic flaws and for monitoring damage evolution by acoustic emission are enumerated and evaluated. 


\section{PREFACE}

Fractures have been found, upon launch, to occur in the control housing of t.he Copperhead missile developed by the U.S. Army. Although the full details of such fractures were not available to the committee, it was learned from two unofficial technical reports and from private communication with Army scientists that the fractures must have occurred in compression and most likely were initiated from locations around cut-outs provided for the protrusion of control fins. The procedure for dealing with the problem by Army scientists was to treat it very conservatively as having resulted from the extension of pre-existing cracks that have been subjected to shear under the overall axial compression of the control housing. This was accompanied by a stress analysis of the control housing under flight loads and the experimental determination of the critical Mode I fracture parameters of the specific alloy of the control housing. Finally, crack inspection maps (CIMAPs) were developed.

Considering other possible ramifications of the problem and to take a broader perspective, the problem was brought to the attention of the National Materials Advisory Board (NMAB) of the National Academy of Sciences which formally established the present committee for the purpose of reviewing the problem of fracture in compression of brittle solids both generally and as it applies to the Copperhead missile system.

The committee met three times to consider and discuss the problem of fracture in compression in a broad way, starting from fundamental mechanisms to phenomenological approaches developed to deal with the problem in a number of brittle solids and including considerations of technological applications. On the basis of these considerations the committee identified two separate behavior patterns in compressive fracture. The first is an extrinsic behavior pattern resulting from large cracks, comparable with the size of the part, amenable to normal approaches of fracture mechanics and dealt. with adequately earlier. The second is an intrinsic behavior pattern resulting from the accumulation of dormant microcracks and culminating in terminal shear faulting that has been analyzed previously as a constitutive instability not amenable t.o treatment by normal procedures of fracture mechanics. It is likely that the failure of the control housing of the Copperhead missile falls into this second category. 



\section{ACKNOWLEDGEMENT}

The committee notes with thanks the contributions of Professor Lallit Anand of the Massachusetts Institute of Technology, the input of Dr. C. H. Sondergeld of The AMOCO Production Company, and the cooperation and support of Mr. Joseph Bluhm, formerly of the U.S. Army Materials and Mechanics Research Center. 

NATIONAL MATERIALS ADVISORY BOARD

COMMITTEE ON FRACTURE IN COMPRESSIVE STRESS FIELDS

Chairman

ALI S. ARGON, Professor, Department of Mechanical Engineering, Massachusetts Institute of Technology, Cambridge

Members

AMOS A. BRADD, Consultant, Philadelphia, Pennsylvania

JOHN D. EMBURY, Professor, Department of Metallurgy and Materials Science, McMaster University, Hamilton, Ontario, Canada

ANTHONY G. EVANS, Professor, Department of Materials Science and Mineral Engineering, University of California, Berkeley

JOHN W. HUTCHINSON, Professor, Division of Applied Sciences, Harvard University, Cambridge, Massachuset.t.s

WILLIAM. H. LEWIS, JR., Manager, Technical Services Department, Lockheed Georgia Company, Marietta

DAVID L. SIKARSKIE, Professor and Chairman, Department of Metallurgy, Mechanics and Materials Science, Michigan State University, East Lansing

TENG-FONG WONG, Professor, Department of Earth and Space Sciences, State University of New York, Stony Brook (formerly Department of Earth and Planetary Sciences, Massachusetts Institute of Technology)

Liaison Representatives

JOSEPH BLUHM, Ketired (formerly Army Materials and Mechanics Kesearch Center, Watertown, Massachusetts)

ROBERT ENGLE, Air Force Wright Aeronautical Laboratory, Wright-Patterson Air Force Base, Ohio

JOSEPH M. KRAFFT, Nava1 Research Laborat.ory, Washingt.on, D.C.

JAMES NEWMAN, National Aeronautics and Space Administration-Langley Kesearch Center, Hampton, Virginia

JEROME PERSH, Staff Specialist for Materials and Structures (Engineering Technology), Department of Defense, Washington, L.C.

JOHN SIMMONS, National Bureau of Standards, Washington, D.C.

$\underline{\text { NMAB }}$

Joseph K. Lane, Staff Metallurgist. 

1 CONCLUSTONS AND RECOMMENDATIONS 1

Conclusions

Recommendations

2 OVERVIEW OF FRACTURE IN COMPRESSION

3 THEORETICAL DEVELOPMENTS

Introduction 13

Mechanistic Models for Isotropic Solids 13

Mechanistic Models for Anisotropic Solids 17

$\begin{array}{ll}\text { Phenomenological Models } & 18\end{array}$

4 EXPERIMENTAL VERIFICATION OF MODELS

Macrocracks in Mode1 Macrosamples 25

Mechanistic Studies of Rock Samples in Compression 26

Evolution of Sources of Shear Faulting 29

Development of Shear Localization 31

Effective Toughness in Shear Fault Propagation 32

5 COMPRESSIVE FRACTURE IN ROCKS 33

Phenomenology and Mechanisms of Rock Fracture 33

Applied Problems in Compressive Fracture of Rocks 42

6 COMPRESSIVE FRACTURE IN CONCRETE, CEMENTED CARBIDES AND. 47

ULTRA-HIGH STRENGTH METALS

Fracture in Concrete $\quad 47$

Fracture in Cemented Carbides 51

Fracture in High-Strength Metals 52

7 COMPRESSIVE FRACTURE IN COMPOSITES 53

8 NONDESTRUCTIVE EVALUATION

$\begin{array}{ll}\text { Int.roduction } & 57\end{array}$

Acoustic Probing Techniques $\quad 58$

Other NDE Techniques $\quad 59$

Flaw Detection Sensitivity and Reliability 59

$\begin{array}{ll}\text { REFERENCES } & 59\end{array}$

$\begin{array}{ll}\text { CURRICULA VITAE } & 65\end{array}$ 

1 Extrinsic fracture in compression initiated from a large crack comparable in size to the dimensions of the part.

2 Development of intrinsic fracture behavior by initiation and propagation of shear faults in compression.

3 Signatures of microcrack accumulation and evolution of a nucleus of a shear fault.

4 Bi-axial fracture criterion for extrinsic behavior, initiated from large shear cracks without and with crack face friction.

5 The reduction of: a) shear stiffness $G_{s}$, and

b) bulk stiffness $K_{s}$ with increasing effective stress $\sigma_{e}$.

6 The increase in "plastic" shear resistance, $\sigma_{e}$, with. pressure, $\sigma_{m}$, in a typical concrete where the apparent "plasticity" arises from an increase of microcracks with increase in shear.

7 Relation between compressive strength and confining pressure for a series of rocks tested at room temperature.

8 Focal mechanisms for acoustic emission events recorded during the uniaxial deformation of Westerly granite.

9 Relationship between shear and normal stresses and principal stresses at failure ranging from tensile to uniaxial compression to compression under a confining pressure.

10 Triaxial compression experiments and the dependence of the fracture angle on the principal stress difference

11 Dependence of compressive strength on the vapor 
FIGURES (cont.)

Page

12 Dependence of compressive strength of rocks on size. $\quad 40$

13 Characteristic force-penetration curves for charcoal 43 grey granite by $2.5 \mathrm{~cm}$ wide wedges.

14 Idealized model of the penetration of a tool wedge 44 int.o rock.

15. Increase of compressive strength of a typical concrete 49 with lateral stress.

16 Increase of compressive strength $\sigma_{1}$ of concrete 50 with confining pressure $\sigma_{3}$.

17 Examples of failure in compression by fiber kinking 54 in a carbon fiber composite. 
CONCLUSIONS AND RECOMMENDATIONS

\section{CONCLUSIONS}

Brittle solids such as rocks, concrete, glass, ceramics, ultra-high-strength metallic alloys with very limited tensile ductility, and certain composites (e.g., cemented carbides) become very sensitive to flaws in tension but exhibit compressive strengths that are several-fold higher. Such solids fracture in compression in one of two qualitatively and mechanistically different forms. In an ext.rinsic mode of fracture, large pre-existing cracks comparable with the dimensions of the part can extend under uniaxial compression or constrained compression when the displacement of the crack surfaces in shear provides opening displacements at the crack tips sufficient to initiate opening mode cracks roughly at right angles to the shear plane. In this mode of fracture, the cracks extend across planes of local maximum principal tension and curve in a direction parallel to the maximum principal axis of compression, to result in the splitting of the part. In an intrinsic mode of fracture, the pre-existing cracks or weak interfaces are very much smaller than part dimensions, and the microcracks that form from them remain small and dormant. The accumulation of such microcracks and their grouping, en echelon, finally results in a shear fault that extends when a critical loading condition is met. Measurements have shown that the specific fracture work in such shear fault extensions is from one to three orders of magnitude larger than the critical tensile fracture work in Mode $I$ or plane strain fracture toughness, as is explained on page 6. Hence, failure by shear faulting in the intrinsic mode is a separate phenomenon and cannot be modeled accurately with data collected from Mode I fracture experiments. Certain composites with unidirectionally aligned fibers undergo a failure mode by kinking that is very similar to shear faulting in brittle solids compressed parallel to the fiber axis.

In intrinsic behavior, the accumulation of microcracks prior to the onset of a shear fault imparts to the solid an apparent plastic behavior with strain hardening. In this behavior the inelastic strain that results 
from microcracking has a dilatational component, and the apparent "hardening" is caused by exhaustion of weak interfaces. Formally, the behavior can be represented by standard procedures developed for plastic solids that exhibit pressure dependent yielding and dilatant plasticity. The "polarization" of the solid by the organized microcracking process imparts to the solid "vertex" behavior whereby the generalized plastic potential surface develops a corner that enhances the development of a shear fault. Although faults are planes of catastrophic failure in homogeneous stress fields, in inhomogeneous stress fields such as those existing in problems of tool penetration, curvilinear shear faults can grow quite stably. Such problems are therefore amenable to solution by extensions of slip line field developments well known in plane plasticity.

The phenomenology of apparent. plasticity in brittle solids due to microcrack accumulation has been developed extensively for concrete but the mechanistic processes have not been widely researched and apparently are of little interest. On the other hand, the mechanisms of microcrack accumulation leading to the development of a shear fault by en echelon action of such cracks have been studied in some detail in rocks by microscopy and acoustic emission. A few similar studies exist for the kinking mode of failure of aligned composites in compression. Very few corresponding studies have been undertaken for the failure in compression of cemented carbides or ultra-high-strength steels (only one such moderately detailed study on cemented carbides was uncovered by the committee).

Since the relatively simpler extrinsic behavior results from pre-existing large cracks comparable in size with the part dimensions, their detection by nondestructive evaluation (NDE) techniques is readily possible, making the prediction and prevention of extrinsic fracture in compression achievable. In intrinsic behavior, however, the natural flaws that produce microcracking are of the order of microstructural dimensions and are ubiquit.ous. This makes their detection not readily possible by NDE techniques, but such detection is of little relevance since the terminal failure by shear faulting is ultimately governed by the main microstructural entity.

There are many applications of compressive fracture that are technologically important, ranging from rock machining operations and stability of mine shafts to microstructural stability in composites. These applications traditionally have been handled by simple extensions of plastic yield criteria such as that of Coulomb and Mohr. More modern and sophisticated techniques now are available, but they have not found wide application in the technical field.

There have been very few known instances where fracture in compression by shear faulting has been responsible for failures in ultra-high-strength alloy structures. The Copperhead missile casing might be a specific example of this type. This report describes formalism and procedure for dealing with such fractures in brittle materials that should be directly applicable to metallic alloys, provided the relevant parameters such as the shear fracture energy are determined experimentally. 
RECOMMENDATIONS

Fundamental Mechanisms

The following studies should be useful in developing a better quantitative understanding of the intrinsic fracture process in compression:

1. Monitoring of sources of acoustic emission to trace the evolution of microcracks clustering in conjunction with relevant macro properties to establish constitutive parameters necessary for bifurcation analysis.

2. Determination of proper parameters relating the critical state of initiation of localization to be used in continuum models of localization.

3. Holographic observation of the early phases of localization in laboratory samples.

4. Computer modeling of microcrack interaction leading to the development. of a nucleus for a shear fault.

5. Adaptation of results of bifurcation analyses to obtain bi-axial criteria for fracture in compression.

6. Analysis for continuum bifurcation in transversely anisotropic materials.

7. Relation of NDE signatures to compressive failure in brittle solids and structures to identify the scale of the fault nucleus.

8. Effect of environments on the local fracture processes in both extrinsic (large crack), and intrinsic (en echelon micro-crack accumulation) fracture in compression.

\section{Applications}

The following studies or developments should be useful in achieving better control of compressive fracture in technological applications:

1. Analysis of damage growth in nonhomogeneous stress fields as in chip formation in rock machining.

2. Development of modified plane plasticity slip line theory approaches to deal with shear localization problems in inhomogeneous strain fields.

3. Initiation of laboratory studies of compressive fracture in ultra-high strength steel and in cemented carbides to study the mode of fracture and to measure relevant fracture energy parameters.

4. Study of the effect of increased matrix plastic resistance on the compressive strength of fiber-reinforced composites. 
2

OVERVIEW OF FRACTURE IN COMPRESSION

Fracture on the atomic scale is always a tensile phenomenon in which separating displacements are necessary in a solid to achieve separation of parts. In most structural alloys the fracture process involves the nucleation and plastic growth of voids to final linkage, producing separation of parts of the solid where high stresses may only be reached during interface separation while the plastic expansion of cavities occurs under prevailing plastic flow stresses. This so-called ductile fracture is not of interest here; this report is concerned only with fracture in brittle solids with no or very limited capacity for plastic deformation under normal usage. In such materials, separation of parts requires, at least in very local regions, the attainment of the cohesive strength of the solid by concentration of stress. Since the time of Griffith (1920), it has been appreciated that the strength of brittle solids in tension is governed by crack-like flaws that act as stress concentrators. These cracks may be present intrinsically due to the failure of weak heterogeneities or weak interfaces by differential thermal expansion or they may result from mechanical damage. The condition of propagation of such cracks in brittle solids is the subject of linear elastic fracture mechanics (LEFM) pioneered by Irwin (1957). Crack propagation occurs when the Mode I stress intensity, $\mathrm{K}_{\mathrm{I}}$, for the tensile opening of a crack reaches a critical value, $\mathrm{K}_{\mathrm{IC}}$, known as the fracture toughness. $K_{I C}$ is a material property and is governed by the elastic and cohesive properties of the solid. A vast body of literature exists now for the computation of the Mode I stress intensity factors $K_{I}$ for parts of given shape having cracks of known length and subjected to an external stress (Tada et al. 1972). On the other hand the material parameters that affect the critical stress intensity factor $K_{I C}$ in both homogeneous and heterogeneous brittle solids also are quite well understood in principle even though specific cases are still the subject of much present research. Thus, the phenomenology and mechanisms of the fracture of a flawed brittle solid in tension are clearly understood and procedures for dealing with the problem are well established. 
That brittle solids also can fracture in compressive loading is less well known in structural mechanics but is a familiar problem in civil engineering where large concrete and earthen structures are widely used under gravity loading and in rock mechanics where controlled fracturing is a procedure in excavation and resource recovery. Griffith, who pioneered the understanding of brittle fracture in tension, also was the first to elucidate brittle fracture in compression (Griffith 1924). In a solid containing cracks of many orientations, local tensile fracture can be achieved in triaxial compression when shear stresses produced by unequal compression displace surfaces of cracks against frictional forces and produce tensile stresses near the tips of such cracks (Figure 1a). When locally critical conditions are achieved at the tips of such sheared cracks, extension occurs parallel to the direction of maximum compressive stress and across the direction of the minimum compressive stress (Figure 1b). In this type of fracture, the sliding crack faces clearly act as a jack to pry apart the vertical crack as they release the local shear stress. In truly brittle solids of infinite extent under simple compression (i.e., without a transverse compressive stress), the secondary cracks typically can grow to about 10 to 15 times the length of the initial crack (depending on whether the crack face friction is large or small) before the local shear stress across the crack faces is released to the level of the frictional traction. The presence of transverse compression limits the growth of the secondary cracks to only a few multiples of the initial crack length. Thus, the local fracture of the part due to the jacking action of the sliding interfaces of pre-existing cracks can result in overall fracture of the body only when the initial cracks have lengths comparable with the dimensions of the body. Whenever the body is very much larger than the length of the pre-existing cracks in it, the jacking action of the sliding crack faces cannot produce overall fracture in the part. In such cases the sigmoidal extension of the worst microcrack is followed by the extension of other isolated microcracks under increasing compression. This may occur first quite homogeneously over the body and is the source of the "apparent plasticity" of brittle solids and the dilatational component of strain superimposed on the overall volumetric compression. Eventually, however, interactions occur between sigmoidal cracks resulting in their clustering en echelon as illustrated in Figure $2 a$ where three microcracks are shown to have lined up to increase the overall shear compliance inside the dotted contour. The shear compliance can increase further under increased compression as additional microcracking events become preferentially added at the tip regions $P$ and $P^{\prime}$ due to the concentration of shear stress there. This develops the nucleus of a shear fault instability that spreads over large distances as shown in Figure $2 b$. The exact size of the critical nucleus where a load drop begins will be sensitive to microstructural detail and has not been fully investigated. When the zone spreads across the part, the processes inside the dotted contour become quite complex since much fragmentation is produced under the large relative displacements that lower the shear resistance of the plane and catalyze the instability further to produce concentration of translation under dropping external stresses. The overall faulting behavior of the solid produces a characteristic pattern of macroscopic mechanical behavior that is idealized in Figure 3, where all compressive stresses, compressive displacements, and strains are represented as positive as is the custom in the field of compressive behavior of brittle solids. Figure 3a shows a somewhat idealized "typical" mechanical response of a brittle solid undergoing shear faulting. The region of high compliance during initial 

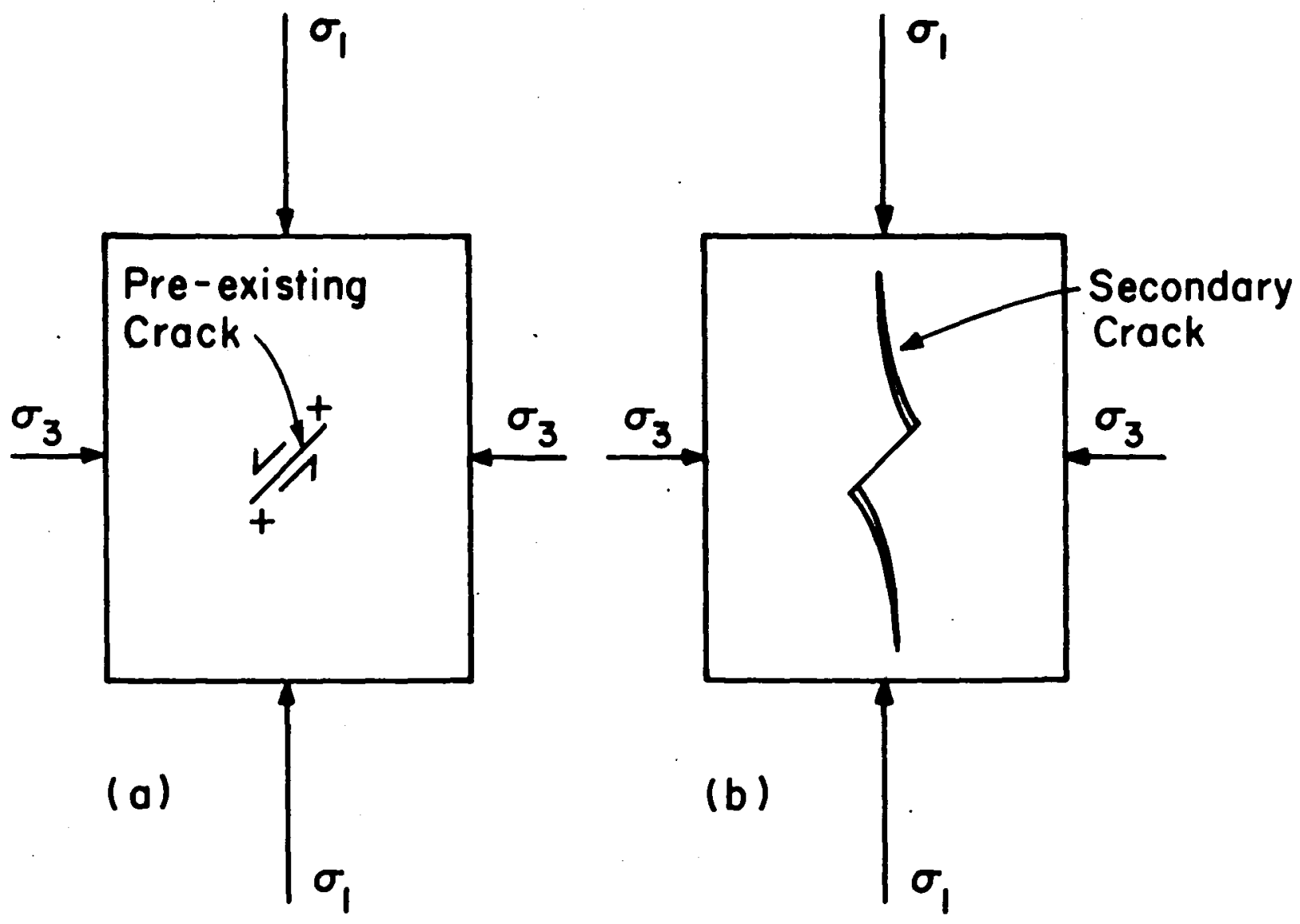

FIGURE 1 Extrinsic fracture in compression initiated from a large crack comparable in size to the dimensions of the part: (a) stresses are concentrated at the ends of a shearing crack and (b) microcracks extend from the shear crack parallel to the principal compression direction. 

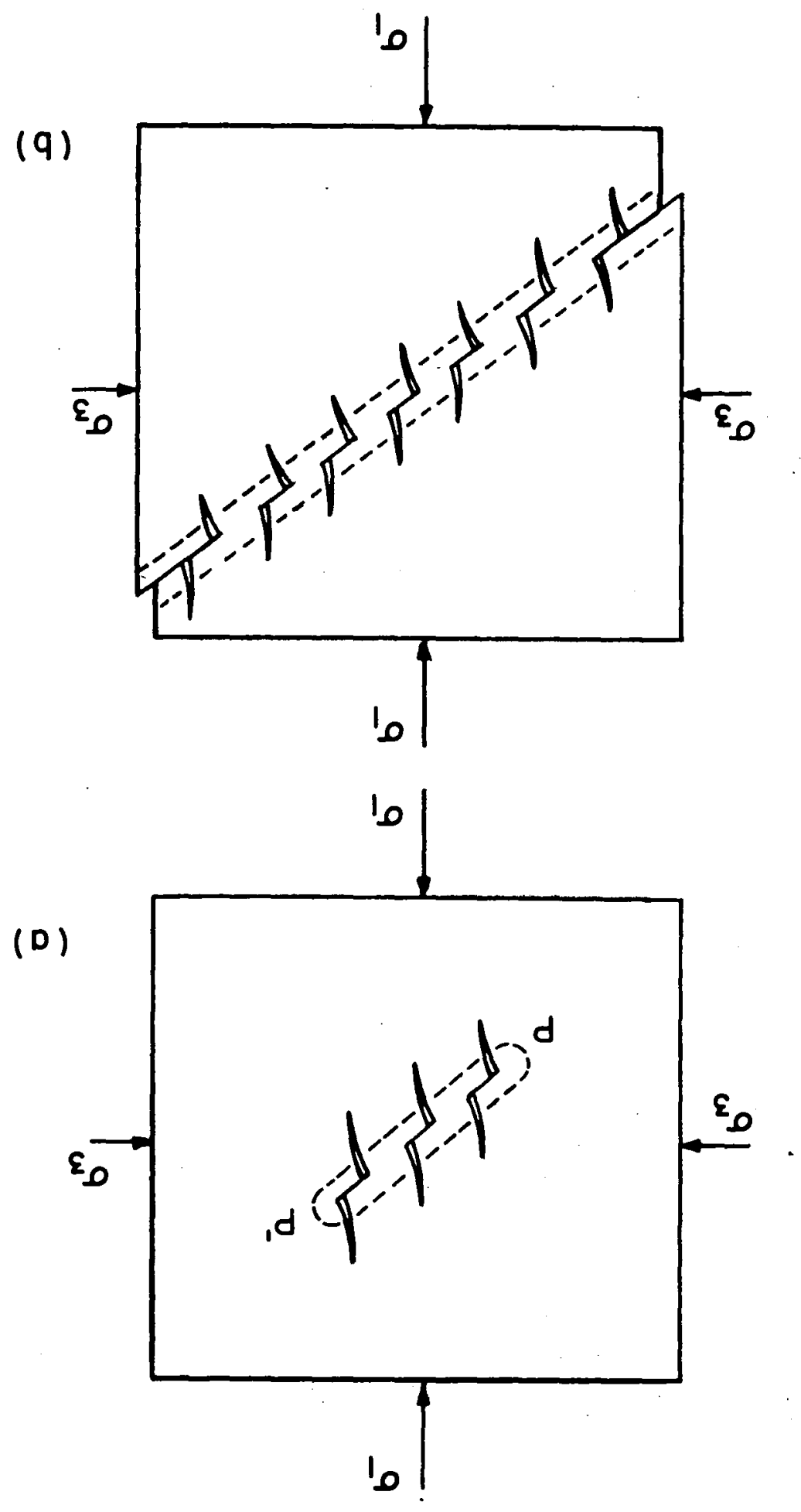

FIGURE 2 Development of intrinsic fracture behavior by initiation and propagation of shear fault in compression: (a) the beginning of en echelon action of adjacent microcracks producing a zone of increased shear compliance and (b) the idealized spread of the high compliance zone across the part resulting in a shear fault. 

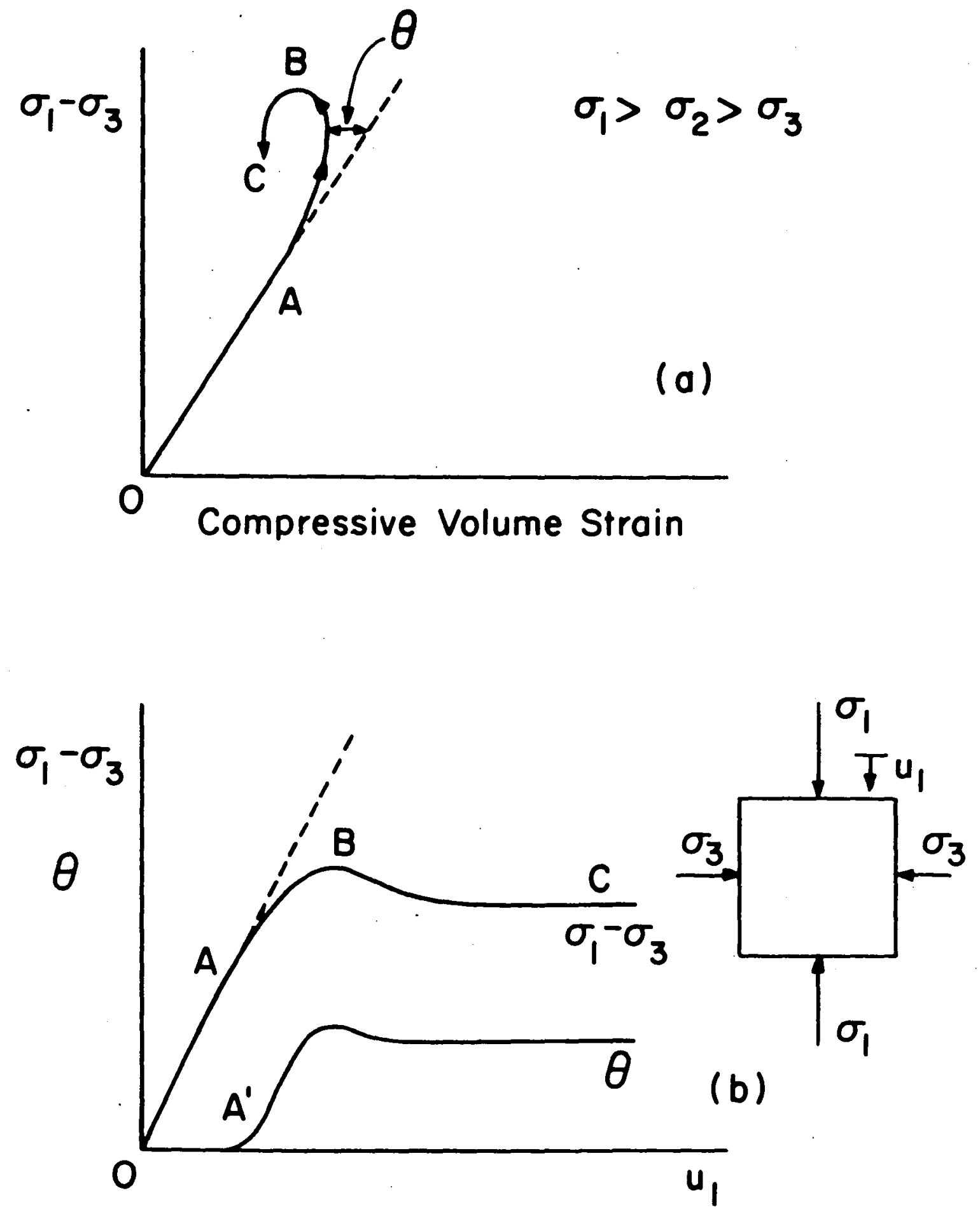

FIGURE 3 Signatures of microcrack accumulation and evolution of a nucleus of a shear fault: (a) dependence of compressive volumetric strain on net compressive stress $\left(\sigma_{1}-\sigma_{3}\right)$, showing the increased inelastic dilatation due to microcracking along path $A B$ and the unloading upon faulting along path $B C$ and (b) dependence of net compressive stress $\left(\sigma_{1}-\sigma_{3}\right)$ and dilatation $\theta$ on compressive displacement $u_{1}$. 
loading that results from the closure of pre-existing cracks and pores is not shown for clarity. The line OA represents the compressive response of the intact solid to increasing maximum compressive stress bias, $\left(\sigma_{1}-\right.$ $\sigma_{3}$ ). At point A dormant sigmoidal microcracking begins and a measurable component of superimposed dilation becomes observable. First, quasi-homogeneous microcrack filling of the part and then interactive en echelon associations of microcracks occur between $A$ and $B$. Recent acoustic emission measurements have indicated that the filling of the sample with microcracks is never quite random in even the very early stages, and that. associations among microcracking events begin very early in the process. Near the point $B$, a nucleus of a faulting zone has fully developed and spreading of the fault zone occurs between $B$ and $C$ under dropping compression. At. $\mathrm{C}$, a fully active zone of shear faulting has developed. Figure 3b shows a more expanded version of this behavior where the compressive stress bias $\left(\sigma_{1}-\sigma_{3}\right)$ and the developing inelastic dilatational strain $\theta$ are plotted as a function of compressive displacement. $u_{1}$ in the direction of the maximum principal compressive stress.

Given the above description of failure in compression of brittle solids it is useful to distinguish two different failure processes even though both depend ultimately on tensile separation of material on the atomic scale. The first process of failure involves the sigmoidal extension of a single crack arising from the jacking action of a single set of pre-existing crack interfaces and will be called extrinsic fracture. In this form of fracture, the process is initiated by a large pre-existing crack-1ike flaw that extends unambiguously by satisfying a critical Mode I stress intensity criterion to eventual splitting of the structure. This basic feature remains unaltered whether the interfaces of the pre-existing crack are frictionless as imagined by Griffith (1924) or are subject to friction as modeled more realistically by McClintock and Walsh (1962). In both cases, knowledge of the geometry and the loading condition and information on the Mode I fracture toughness $K_{I C}$ are sufficient to describe the process of crack extension. The second form of fracture, which occurs in tougher brittle solids under transverse stress, begins with the en echelon interaction of sigmoidal cracks to form a nucleus for shear faulting and will be called intrinsic fracture. It is differentiated from extrinsic fracture in that the fault nucleus does not pre-exist but develops gradually by the accumulation of microcracks and in that its spread in shear in the plane of the initial nucleus does not obey a Mode I fracture toughness criterion. In fact, experimental evidence suggests that the effective fracture energy, now in an in-plane shear mode (Mode II), can be several orders of magnitude higher than the tensile fracture toughness $\mathrm{K}_{\mathrm{IC}}$ (see the discussion of effective toughness in shear fault propagation in chapter 4).

Under very large superposed pressures, most brittle, crystalline inorganic solids can undergo true plastic deformation by dislocation glide even at low temperatures. Such plasticity has been observed in many rocks based on laboratory experiments and on transmission electron microscopic work on rock samples revealing deformation that must have resulted from crustal motions in earlier geologic times. Much of the laboratory work on compression under superposed pressure of jacketed, rock samples indicates that the samples probably have undergone only "apparent plasticity" by 
extensive stable microcracking. In glassy solids true plasticity under very large pressures is also possible albeit by mechanisms not involving dislocation motion (Argon 1980).

The remainder of this report will review qualitatively the state of information on both extrinsic and intrinsic brittle fracture in compression in engineering applications. Fracture of rocks, concrete, fibrous composites, cemented carbides, and of ultra-high-strength steels with very low fracture toughness will be covered. Only fracture under monotonically increasing compressive loading where the eventual fracture is of the extrinsic or intrinsic type will be considered. Application areas for the basic criteria for fracture in compression in both structural design and in manufacturing processes such as rock machining will be discussed; however, fracture occurring under repeated compression (e.g., in railroad rails, ball and roller bearings, and rolls of large rolling mills where the fracture is in the nature of contact fatigue resulting from cyclic crack growth) will not be considered. Rolling contact fatigue problems are comparatively well understood and the reader is referred to standard references on the subject such as Harris (1966). 

THEORETICAL DEVELOPMENTS

\section{INTKODUCTION}

The theoretical developments of brittle fracture in compression follow two complementary approaches. In the first, the mechanistic approach, the compressive strength of brittle solids is explained through the stress concentrations that sharp pre-existing cracks produce under different modes of compressive loading. The emphasis is on the elucidation of the mechanism based on the local extension of isolated cracks by the same criterion that makes brittle cracks propagate in tension. In very brittle materials of finite dimensions under compression where the extension of a single crack gives rise to extrinsic fracture behavior, these developments are satisfactory. These mechanistic models will be reviewed below followed by a discussion of how they can be extended to explain the behavior of tougher brittle solids under substantial transverse stress where fracture does not result from a large, single pre-existing crack but rather from the progressive sympathetic interaction of a number of small neighboring cracks leading to the development of a shear fault nucleus and intrinsic fracture. Since such interactions can be handled at best only through evolutionary computer models where the results become sensitive to the details of the models, other asymptotic and partly phenomenological, constitutive models become useful to understand the overall envelope of behavior and they also will be reviewed.

MECHANISTIC MODELS FOR ISOTROPIC SOLIUS

\section{Extrinsic Fracture}

The modern theoretical developments of fracture in compression based on mechanistic models began with the pioneering work of Griffith (1924) who was the first to consider the effects of cracks in brittle solids subjected to 
compression. Based on Griffith's theory and subsequent extensions of it (McClintock and Walsh 1962, Nemat-Nasser and Horii 1982, Sih 1973), the process to be described is known to result in extrinsic failure.

If a brittle solid contains a family of flaws of all orientations that can be idealized as penny-shaped cracks of the same radius, final fracture can result under an unequal set of triaxial stresses by the extension of these cracks. In most cases the two extreme principal stresses govern the behavior. When the algebraically largest principal stress is tensile, fracture occurs from a crack perpendicular to it, regardless of the presence of a transverse compressive stress if that stress is numerically smaller than three times the tensile strength. When the magnitude of the transverse compressive stress becomes numerically larger than three times the magnitude of the tensile strength, the character of the fracture changes as crack extension initiates from slanted cracks that are subjected to shear displacements against the crack wall friction caused by the difference between the two extreme principal stresses. These shear displacements concentrate stress at the crack tip and begin to extend the crack when the critical stress intensity condition, $K_{I C}$, is reached there. The crack then propagates across the direction of the algebraically largest principal stress. As the transverse compressive stress increases, the required largest. principal stress for fracture decreases continuously and even becomes compressive as shown in Figure 4. The compressive strength of such a solid should range between 8 times the tensile strength for no crack wall friction to somewhat higher values with increasing crack wall friction. The mechanism of this mode of fracture is clearly the splitting of the entire body parallel to the largest principal compressive stress and perpendicular to the algebraically largest stress, which is the smallest compressive stress under triaxial compression (see Figure 1). This overall failure mode is possible only in parts that have dimensions a few times the size of the initial crack. This is because the shear stresses on the initial crack are relieved with only small amounts of relative translation producing a small and limited opening wedge for the secondary cracking process. Simple and straightforward estimates show that the secondary cracks cannot extend more than about 10 to 15 times the initial crack length under ideal conditions and that both crack wall friction and transverse compressive stresses reduce this extension to only a few lengths of the initial crack. Except in very small and extensively precracked samples, this will be too short an extension to constitute failure of the part. This form of fracture in compression will be called extrinsic fracture because whenever it is found to govern in substantial size bodies it will be due to the presence of a very large and noncharacteristic crack that is of the order of the part dimensions itself.

There is general agreement that in extrinsic fracture the secondary cracking initiates and eventually terminates when locally the critical stress intensity criterion for Mode $\mathrm{I}$ is met. There is, however, some controversy about whether or not the direction of secondary cracking and the path of the secondary crack are governed by a critical cohesive strength criterion as is implied by Griffith (1924) and specifically used by McClintock and Walsh (1962) or are governed by a requirement of maximum elastic strain energy release as proposed by Sih (1973). In most cases, for a Poisson's ratio around 0.3 , the paths of the secondary crack are too 


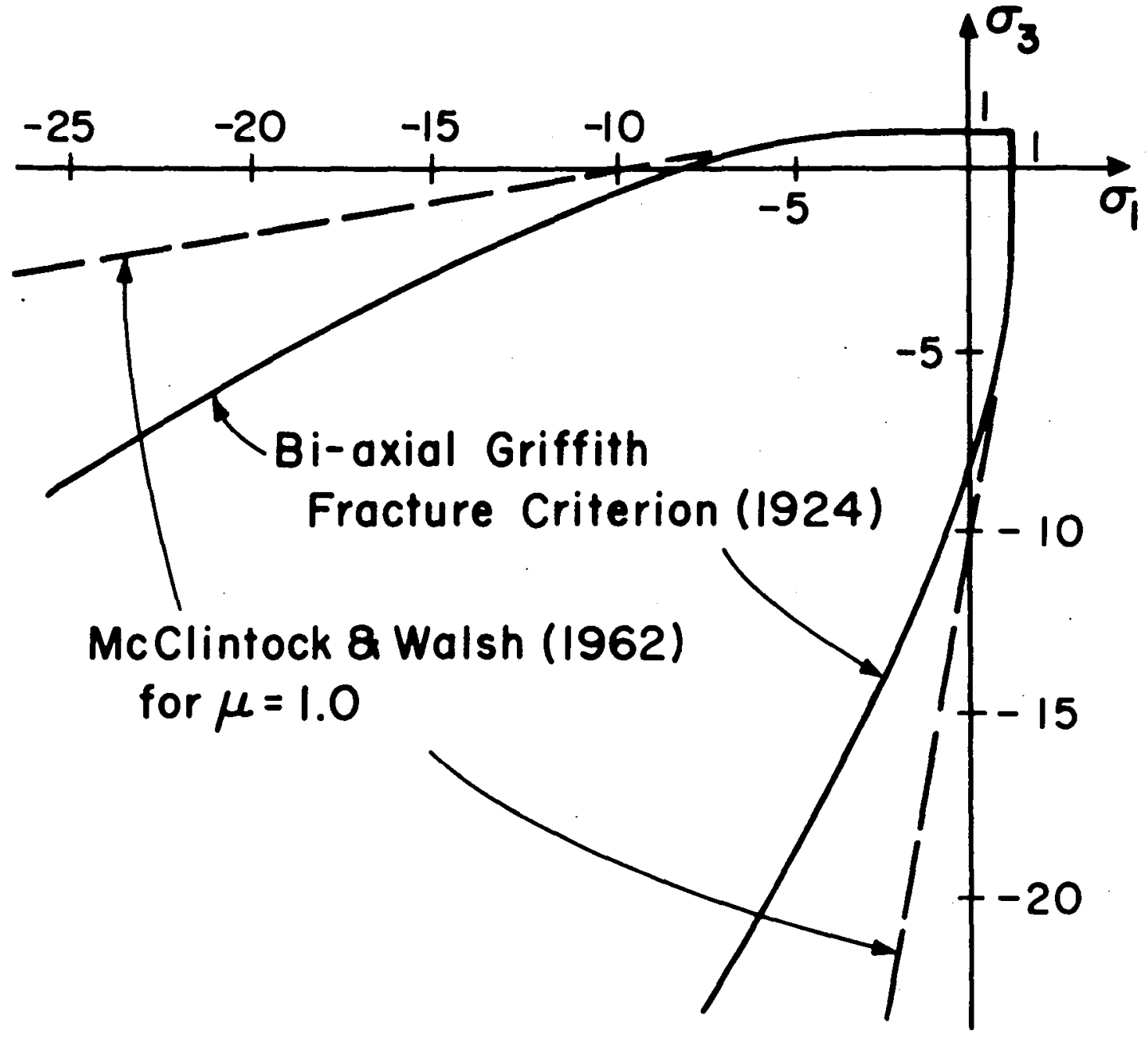

FIGURE 4 Bi-axial fracture criterion for extrinsic behavior, initiated from large shear cracks without (Griffith 1924) and with (McClintock and Walsh 1962) crack face friction. 
similar to distinguish between the two criteria, but more substantial differences should exist for larger or smaller Poisson's ratios. This point will be examined further in chapter 4 when the experimental evidence for various mechanisms is reviewed. This is of little practical importance, however, since extrinsic fracture is rarely observed outside the laboratory. A possible exception may occur in the exfoliation fractures and in rockbursts as discussed by Nemat-Nasser and Horii (1982).

\section{Intrinsic Fracture}

The pre-existing cracks or weak interfaces that govern the st.rength of brittle solids in tension and that might be instrumental in producing fracture in compression usually are very small in relation to the dimensions of the part. In such instances, all slanted cracks that can be made to shear against their crack face friction under unequal triaxial compression will be sigmoidally extended parallel to the maximum principal compressive stress by the wedging action of the slanted crack interfaces as these displace to relieve the local shear stress. This gives rise to measurable dilatational strains but no fracture. With increasing compression additional slanted cracks are progressively "polarized" by extension into the direction of principal compression. These microcracking events initially are uncorrelated but eventually become correlated as new cracking events are added in the vicinity of already clustered microcracks where stresses become concentrated by the increased compliance of the clustered crack region. The correlated accumulation of microcracks eventually leads to the formation of a shear fault nucleus that spreads laterally under decreasing stress (see Figures $2 b, 3 a$, and $3 b$ ).

Kachanov (1982) has attempted to develop a physical theory of inelastic behavior of rocks based in part on the outlined mechanism of sigmoidal microcracking in brittle solids in compression. Kachanov treats two stages of inelastic behavior: frictional sliding of pre-existing microcracks, and the sigmoidal extension involving stable growth. In each case the cracks are assumed to be noninteracting and the contribution from each crack to the overall inelastic strain is determined from the analysis of a penny-shaped crack in an infinite elastic body subject to remote stressing. As in the McClintock and Walsh mode1, Coulomb friction between the two faces of the initial microcrack is assumed and must be overcome if relative sliding is to occur. The amount of sliding on a given crack is inherently a path-dependent process in that the amount and sense of sliding depends on the history of stressing to reach a given stress state. Thus, inelastic behavior resulting from sliding and crack propagation is generally path-dependent and, like plasticity, can be described only for arbitrary stress histories by incremental relations. However, just as in the physical theory of plasticity, Kachanov shows that there is 1 imited path-independence for stress histories that do not depart too much from proportional loading. Since Kachanov's model does not involve the modification of the applied stress field by crack sliding and subsequent microcrack extension, consecutively correlated cracking is not modeled and the inelastic deformation never reaches the all-important condition for shear faulting. 
There are no theoretical studies of the development of shear faults by the preferential and correlated clustering of microcracks, en echelon, under compression. The corresponding problem of damage clustering in biaxial tension has been modeled by McClintock and Mayson (1976) to clarify the effect of variability of local strength on the mode of damage accumulation leading to an eventual tensile fracture instability. There is some need for repeating a similar analysis based on the statistical aggregation of sigmoidal microcracks under unequal triaxial compression. As will be discussed below, considerable progress has been made, however, in dealing with the problem of shear faulting by developing phenomenological constitutive laws that describe a terminal envelope of behavior making use of the inelastic properties of dilating and pressure-dependent continua.

\section{MECHANISTIC MODELS FOR ANISOTROPIC SOLIDS}

The process of intrinsic fracture culminating in the development of a shear fault under compression has been prominently observed.in fiber composites in the form of kink bands. The mode of failure initiated by correlations of local simple shear processes into a band with boundaries perpendicular to the shear direction was observed first by Mugge (1898) in compressed crystals of disthene and more recently by Orowan (1942) in zinc single crystals. The latter elucidated the geometrical aspects of the failure and labeled it as kinking. The process as such is well known in crystal plasticity. It received some early theoretical attention by Frank and Stroh (1952) who provided estimates of stresses around partially formed kink bands that serve to propagate the bands. Kinking also has been known as an important mode of failure of wood since early days of aviation when that material was used widely for lightweight aircraft structures. In more recent times compressive failure by kink band formation has re-emerged as an important problem in the compressive failure of aligned fiber composites and even as an internal failure mode in highly oriented single polymer fibers. Kinking in fiber composites is accompanied by fiber fracture at the kink boundaries, and therefore has been recognized as a damage mechanism that both limits the compressive load-bearing capacity of the material or structure and substantially enhances the failure susceptibility in the presence of subsequent tension.

The initial analysis of the kinking phenomenon in fiber composites by Rosen (1967) was based on the premise that failure occurred by in-phase or out-of-phase buckling in unison of parallel fibers in an elastic matrix of lower modulus. This elastic analysis was found to give buckling stresses that were far too high. The discrepancy could not be reduced significantly by considering imperfections (Budiansky 1983) in this microstructural buckling analysis.

The analogy of the fiber kinking process to the development of kink bands in hexagonal metal crystals has suggested that the formation of kink bands must involve inelastic deformations in the matrix initiated locally at. regions of small fiber misalignment. This mechanism has been analyzed approximately by Argon (1972) and more elaborately by Budiansky (1983). Both emphasized the high imperfection sensitivity of the process of band nucleation where the compressive strength is found to be directly 
proportional to the shear yield strength of the matrix and inversely proportional to the angle of misalignment between the axes of the fibers and the axis of the maximum principal compressive stress. Although it is clear that the angle such kink bands make with the compression axis or with the direction of fiber alignment must depend on the internal shear strain inside the band, the fiber diameters, and the fracture strength of the fibers, the state of understanding of what governs the observed inclinations of bands is not satisfactory. The strong dependence of the compressive strength on the misorientation of the fiber bundles with the axis of maximum principal compression makes the compressive strength very orientation-sensitive and puts emphasis on the improvement of the shear strength of the mat.rix in such composites.

\section{PHENOMENOLOGICAL MODELS}

\section{Deformation Theory}

In phenomenological theories for isotropic materials, whether based on total deformation or on deformation increments, the conditions of deformation must depend on invariants of the stress tensor. Of these, the first invariant, $\mathrm{J}_{1}$, is proportional to the negative pressure component of the stress tensor whereas the second invariant, $J_{2}$, represents a scalar measure of deviation of the stress state from a pure negative pressure and, thus, defines a deviatoric stress or effective stress that initiates and maintains inelastic deformation. In physically based theories of inelastic material response, the constitutive behavior of the material involves connections between the total deformation or the deformation increment with the negative pressure and the effective stress or, stated more abstractly, the two invariants of the stress tensor.

In a deformation theory, the most general relation between strain and stress for the restricted class of stress responses called monotonic proportional loading, the total strain is a function of the negative pressure and the effective stress with the coefficients of proportionality being themselves functions of the negative pressure and the effective stress. With metals for which the negative pressure has a negligible influence on yield and where the plastic strains are incompressible, the constitutive relation depends only on the effective stress. In the $\mathrm{J}_{2}$ deformation theory of such materials, the coefficients $f$ and $g$, prescribing the dependents of the total strain on the negative pressure and effective stress, are inversely proportional to the elastic bulk modulus $K$ and the secant modulus $G_{s}$ of the pure shear stress-strain curve, respectively, where the latter becomes the elastic shear modulus in the elastic range.

For compressive proportional loading of brittle and semi-brittle materials, the most systematic analysis of experimental data has been carried out for concrete. Kupfer and Gerstle (1973) analyzed data on biaxial tests and found that the coefficients $f$ and $g$ for a particular concrete were $\mathrm{K}_{\mathrm{s}} / 3$ and $\mathrm{G}_{\mathrm{s}} / 2$, respectively, when $\mathrm{K}_{\mathrm{s}}$ (the secant modulus of the curve of dilation versus mean stress) and $G_{s}$ (as defined above) were assumed to depend only on the effective stress $\sigma_{e}$. The functional dependence of $K_{s}$ and $G_{s}$ on $\sigma_{e}$ found by Kupfer and Gerstle (1973) is 
illustrated in Figure 5. The experimental data are represented schematically as the dashed curves; the increased volumetric and shear compliance illustrated is interpreted to come from microcracking.

Subsequent to Kupfer and Gerstle's work, a cooperative study involving seven laboratories was undertaken (Gerstle et al. 1980) to explore the effect of different test procedures on the proportional loading data. A single concrete was prepared in one laboratory and then was tested at the same age in each of the laboratories. Both biaxial and triaxial data were obtained, enlarging the span of the proportional loading histories. The earlier constitutive response proposed by Kupfer and Gerstle (1973) was found to be inadequate to correlate data from the enlarged span of proportional loadings. In particular, it was found that there was a coupling between volumetric strain and sufficiently large effective stress even when the mean stress was zero, indicating that dilation was produced by shear.

These efforts to describe proportional compressive loading of concrete illustrate the difficulty of representing dilatational microcrack "plasticity" by simple phenomenological forms. Bazant and Tsubaki (1980) have proposed more elaborate functional forms to extend the range of validity of the simple constitutive relation between strains and the two invariants of stress. Similar phenomenological attempts to describe the proportional loading response of rocks do not appear to have been made.

In analyzing shear banding it is necessary to express the response of the material in a given state in incremental form. Generalizing from the deformation theory, it is possible to state a differential constitutive connection between strain rates and stress rates where the incremental moduli relating them depend on the effective stress and negative pressure through the coefficients $f$ and $g$ introduced above and their first partial derivatives. These incremental moduli are useful in connection with the analysis of the onset of shear bands.

\section{Incremental Theory}

There have been many developments in recent years proposing incremental constitutive relations for brittle solids such as concrete and rocks (e.g., Anand 1980, Bazant and Kim 1979, Nemat-Nasser and Shokooh 1980). Most of these involve pressure-dependent yielding and inelastic volume change but otherwise have features in common with the flow theories of metal plasticity. In the form of the relation proposed by Rudnicki and Rice (1975), the problem is handled as a generalization of: the classical Prandt1-Reuss relation to which the development returns when the pressure dependence of yielding and the inelastic dilatancy are suppressed. In this generalization the yield condition is considered to be pressure dependent (Figure 6) and the material is considered to have a dilatant response during loading but a typically elastic response during unloading. With either the deformation theory or the incremental flow theory as outlined above in connection with concrete, the object is to model the quasihomogeneous response of the material prior to localization. When localization occurs as in the shear faulting process in brittle substances under compression, the 

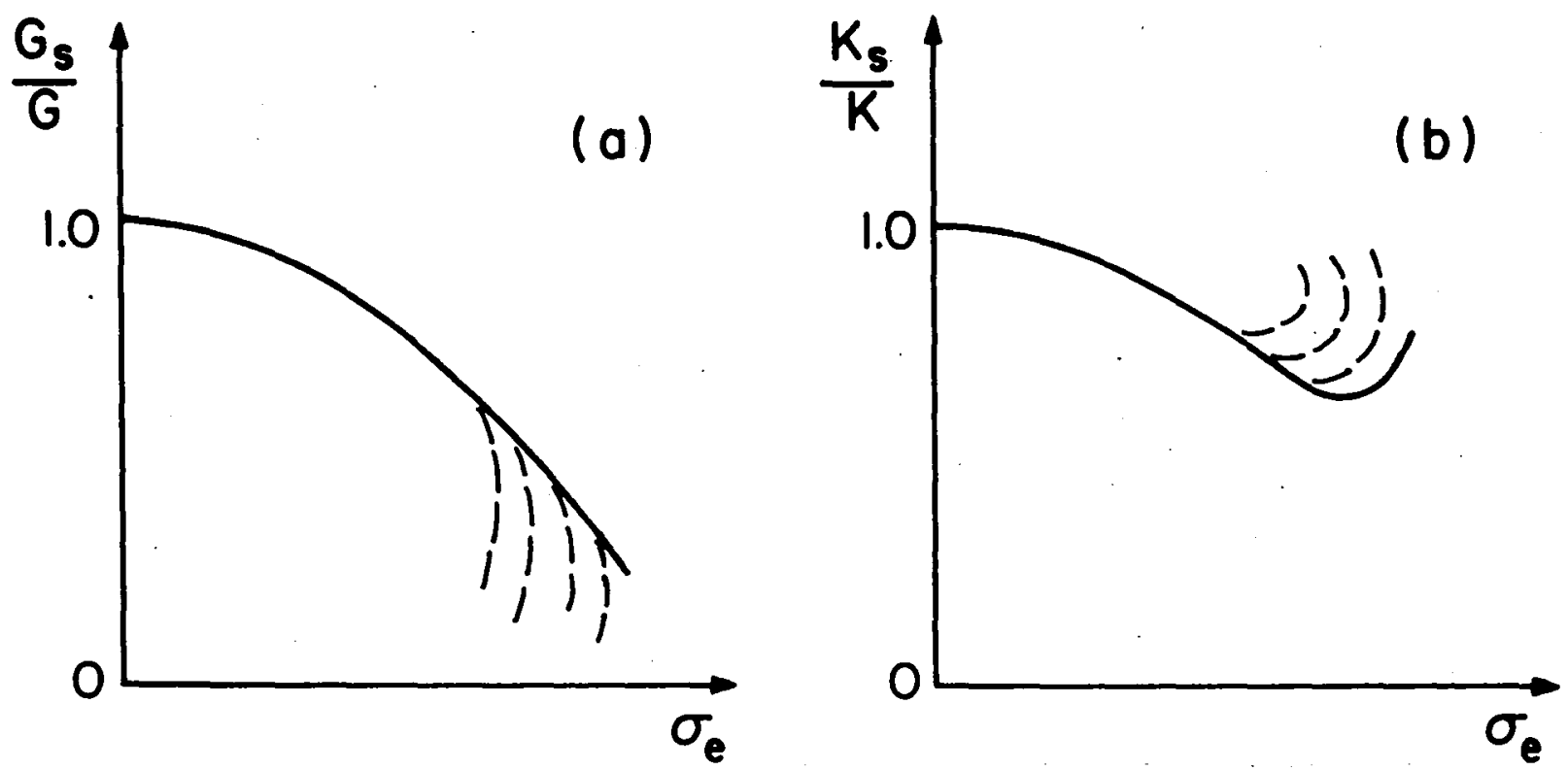

FIGUKE 5 The reduction of: (a) shear stiffness $G_{s}$ and (b) bulk stiffness $K_{s}$ with increasing effective stress $\sigma_{e}$, both normalized with the behavior of the initial intact solid, for a typical brittle solid such as concrete before the eventual shear fault instability. 


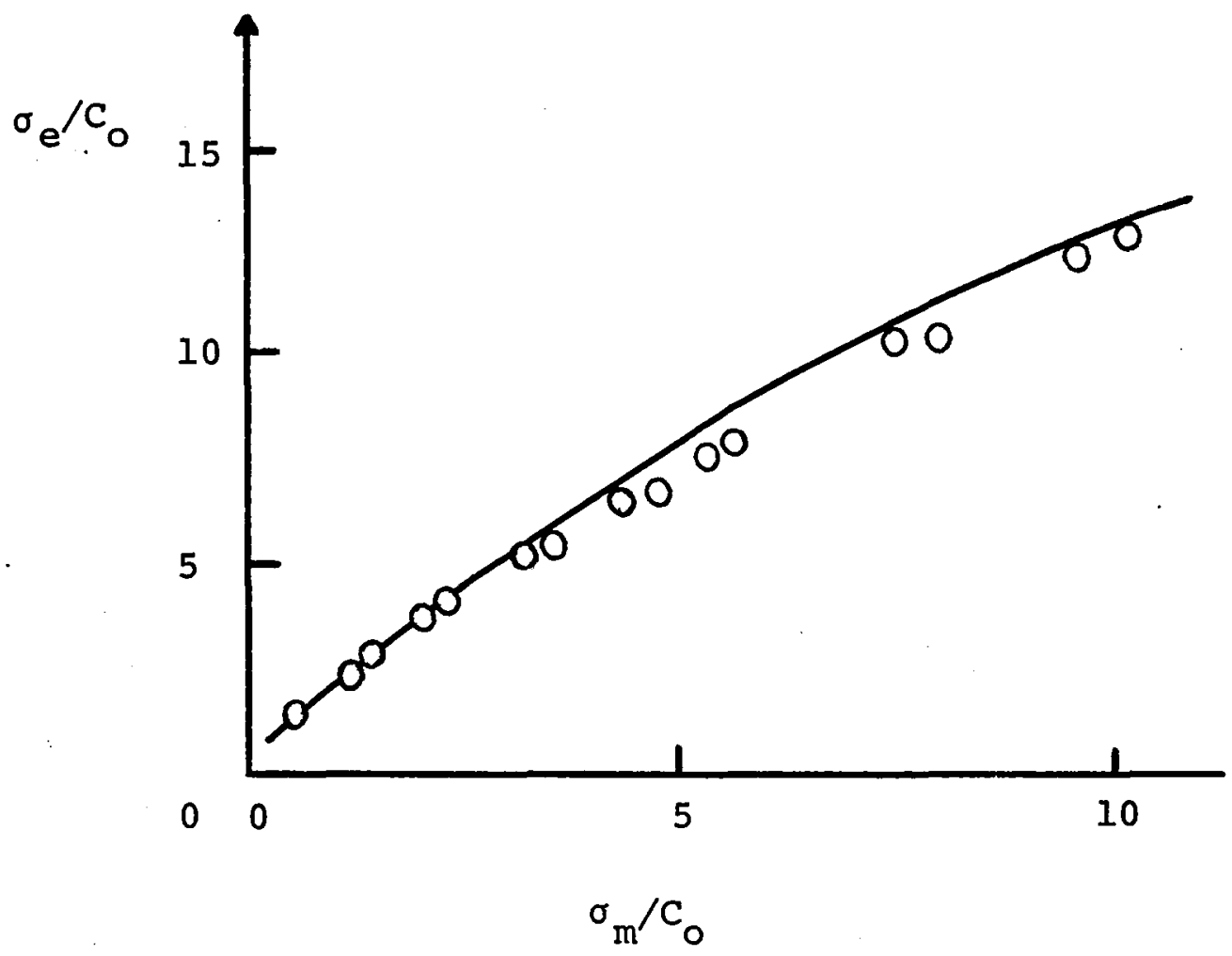

FIGURE 6 The increase in "plastic" shear resistance, $\sigma_{e}$, with pressure, $\sigma_{m}$, in a typical concrete where the apparent. "plasticity" arises from an increase of microcracks with increase in shear. The scale factor $\mathrm{C}_{\mathrm{O}}$ is the uniaxial compressive strength of the unconfined concrete (Chen 1982). 
mechanical response of the material becomes inhomogeneous, or it bifurcates into a region of a "band" in which deformation intensifies and a "matrix" in which deformation decelerates, stops, and is often followed by unloading.

\section{Formation of Shear Bands}

Given a constitutive description of the material for compressive deformation histories such as those described above, it is necessary to ask at what point in any given history will homogeneous deformation terminate and give way to nonhomogeneous deformation, increasingly localized into bands. The onset of localized banding does not necessarily constitute final failure of a material element, but it presumably is at least the beginning of the primary failure process under compressive loading. Here the concern is with intrinsic localization expected to occur in any material element that reaches a critical deformation state.

Rudnicki and kice (1975) have considered in detail the conditions for shear band formation or so-called bifurcation of deformation in shear under imposed uniaxial compression. In this development the width of the localization band cannot be specified but is recognized to be governed by the principal scale of the microstructure, which is usually the grain size. The analysis assumes further that the constitutive behavior of the material, in what will become the shear band, is the same as that operating outside the band at the onset of the localization. Thus, the onset of the banding does not need to be ascribed to the appearance of a new mode of microstructural deformation not already active in the homogeneous regime. Whether this is actually the case for the materials that exhibit band formation remains to be established by experimentation. Of course deformation in a fully developed band will almost certainly bring into play additional microevents such as microcrack coalescence in compressive fracture of brittle solids, as idealized in Figures $2 a$ and $2 b$, that is of interest here.

The analysis of Rudnicki and Rice (1975) begins by assuming that total loading is present both inside and outside the band in the increment following the onset of bifurcation so that the same incremental moduli are operational everywhere at that stage. The analysis then proceeds by searching in the deforming continuum for possible planar zones of undeterminable width across the borders of which a jump in the velocity gradient can be admitted under no jump in tractions. For a shear band in a nondilating material the direction of displacement increment across the border of the band must be inextensional and, therefore, parallel to the plane of the border of the band whereas in dilating material this direction can have a component out of the plane.

The strain at which shear bands are first predicted to emerge depends very strongly on the incremental moduli used in evaluating the condition of bifurcation described above. In metals when porosity does not develop, the analysis predicts that shear bands will not occur, except possibly at exceedingly large strains or in a state of plane strain compression (or tension) even zero or slightly negative strain hardening rates will not precipitate shear bands. On the other hand, predictions for the onset of shear bands using incremental moduli from deformation theory do indicate the 
possibility of band occurrence at strain levels that are at least qualitatively in accord with experimental observations. Bifurcation under total loading conditions is possible as long as the shear in the band develops gradually with continuing overall straining. As the band forms, the deformation deviates more and more from proportional loading and the total loading condition ceases to be met. Most likely, calculations of the onset of shear banding based on deformation theory moduli provide a lower bound to their actual occurrence, assuming that initial material nonuniformities are not playing a significant role.

The analyses referred to above treat the shear localization as a volume phenomenon in which the onset of the instability can be hastened by initial imperfections. Since imperfections are likely to be more pronounced on a free surface, initiation of shear banding from a free surface is likely. 
EXPERIMENTAL VERIFICATION OF MODELS

\section{MACROCRACKS IN MODEL MACROSAMPLES}

A number of investigators (Erdogan and Sih 1963, Brace and Bombolakis 1963, McClintock 1964, Hoek and Bieniawski 1966) have performed experiments on transparent rectangular plates of plexiglass or plate glass containing large initial through-the-thickness cracks making different angles with the specimen edges. These plates were subjected to compression in the plane of the plate to obtain the sigmoidal fracture predicted by Griffith (1924). The observations were qualitatively in support of the predictions in that the secondary fractures that initiated from the tip regions of the pre-existing large crack were perpendicular to the surfaces of the plates and propagated eventually into the direction of compression, splitting the sample into two pieces. Apart from some measurements made by Erdogan and Sih (1963) of the initial angle of inclination of the secondary cracks with the plane of the initial crack in plexiglass samples tested in tension and measurements of ratios of compressive strength to tensile strength in the precracked plate glass samples of Hoek and Bieniawski (1966), no complete sets of measurements were made to permit a quantitative comparison of the experiments with the theory of Griffith (1924) or its modification by McClintock and Walsh (1962) t.o account for the crack face friction. In spite of these deficiencies, however, the qualitative agreements of the observations with the predictions of Griffith's model of crack extension arising from the shear displacement of crack faces under compression is good. No laboratory observations appear to have been made of the behavior of very large transparent plates containing small through-thickness precracks, to indicate if such cracks can propagate large distances to produce overall failure of the plates in compression. Since such experiments have been performed in much more complex rock samples with weak grain boundaries, this deficiency is not considered serious. 
MECHANISTIC STUDIES OF ROCK SAMPLES IN COMPRESSION

Without doubt, rocks have been the most thoroughly studied brittle substances in compressive loading with and without superposed transverse pressure. The most definitive mechanistic studies of incremental monotonic loading have been performed on rocks to follow the evolution of the stable microcracking process leading eventually to the development of a quasilenticular nucleus of enhanced shear compliance that triggers a terminal shear fault. The overall phenomenology and microstructural details of the failure process in compression will be discussed in chapter 5; here the focus will be only on the portion of the studies pertaining to the verification of the mechanistic models of fracture.

It is important to note that rocks encompass a large family of complex and often heterogeneous inorganic materials with a very large range in inherent plastic resistance at low temperatures. Only those in which intrinsic dislocation plasticity is negligible or absent in the range of interest are considered here. It should be noted that rocks normally contain, even in their virgin state, a large density of microcracks. These can be due either to fractures occurring at earlier times during the "ascent" of the rock to the earth's surface due to geologic processes, or to weak interfaces in sedimentary rocks. In addition, grain boundaries very often are planes of weakness in polycrystalline rocks. Thus, it is clear that laboratory samples of polycrystalline rocks already are extensively precracked or weakened along many randomly oriented interfaces, with the precracks having a spectrum of dimensions roughly in the range of the grain size of the rock.

A thorough study by Hadley (1976) showed that in virgin granite two types of initial discontinuities are prevalent in grains roughly of mm size: pores of dimensions less than about $5 \mu \mathrm{m}$ and aspect ratios of 0.1 to 1 and microcracks of a length of about $100 \mu \mathrm{m}$ and aspect ratios ranging from $10^{-4}$ to $10^{2}$. The presence of these precracks is best indicated by the large initial uniaxial compressive compliance of the rocks that decreases sharply upon application of compressive stress or pressure to the level of the compliance of an uncracked solid sample. Recent studies (Batzle et al. 1980, Kranz 1979, Tapponnier and Brace 1976, Wong 1982b) using the scanning electron microscope (SEM) to follow the incremental evolution of the microcracking process and dilatancy development have provided a good picture of the specific mechanisms. In most of these studies identically prepared but different samples were compressed in the presence of substantial transverse pressure and retrieved at different stages of compression along the loading path to final instability (path A-B in Figure 3a), followed by sectioning, polishing, and scanning electron microscopy. Observations showed that the microcracks due to compression could be distinguished from the pre-existing ones by their orientation and by their being sharp tipped and relatively straight. Compression-induced cracks generally lie within an angle of 15 degrees with the compression axis. Using a testing machine having particularly high stiffness, Wong (1982b) obtained for SEM observation complete suites of granite samples deformed stably through the post-failure region (path $B-C$ in Figure $3 a$ ). These SEM observations revealed a complex set of processes leading to final localization in this relatively isotropic rock with low initial porosity 
(about 1 percent). The inception of localized shear faulting extending over two or more grains was accompanied by the following microstructural processes: (1) geometrical instability of slender lamellae in grains segmented by parallel microcracks, (2) rotation and crushing of "joint blocks" formed by cracks emanating from pores in plagioclase grains, and (3) linking of damage by kinking in biotite grains. Examination of samples after failure showed linking of this damage into shear zones at angles favorably oriented for shear displacement, apparently, even in the presence of friction. Such observations have established that the microcracks due t.o compression can initiate from pre-existing microcracks found at earlier times in the life of the rock, from pores, and from weak grain boundaries and interphase boundaries. The wedging open of these microcracks appears to be governed not only by the sliding displacements of the faces of pre-existing microcracks inclined to the principal compression direction, but also by effective misfit developed under stress due to elastic inhomogeneities between different phases. A detailed statistical study of observed microscale orientations carried out by Wong (1982c) has given some support to the presence of the sigmoidal crack extension process predicted by Griffith (1924). There have been no unambiguous observations of this process in rocks comparable to those reported in laboratory samples of transparent glass plates.

A large number of measurements have been performed on the compressive strength under transverse pressure of a variety of brittle rock samples to test the criterion of Griffith (1924) and its modification by McClintock and Walsh (1962) to account for crack face friction. These measurements are shown in Figure 7 together with the predictions of Griffith for frictionless precracks and those of McClintock and Walsh for precracks with a coefficient of friction of unity (dash-dotted line); the difference between the principal compressive stress, $\sigma_{1}$, and the confining pressure, $\sigma_{3}$, normalized by the compressive strength of $\mathrm{C}_{0}$ of the unconfined samples is plotted against the normalized confining pressure $\sigma_{3} / c_{0}$. Clearly, Griffith's prediction which ignores the crack face friction, is rather poor whereas the predictions based on McClintock and Walsh's model give an overestimate. As already clarified in chapter 3, it is now quite clear that the sigmoidal extensions of the precracks under crack face friction could not possibly be more than one or two initial crack lengths before the shear stress across the initial precracks is relieved to the level of the frictional resistance and, thus, cannot constitute overall failure. Hence, it is surprising that the model of McClintock and Walsh (1962), based on a single crack, with a choice of a coefficient of friction of slightly less than unity, can give reasonably good agreement with the experimental results, all of which were based on the development of shear faulting. A possible explanation of this is the rather uniformly and extensively weakened nature of the initial states of the rock samples making all volume elements have precracks of rather similar lengths and effectively only a narrow distribution of strengths. In this way the condition to initially. achieve sigmoidal microcrack extension leads in quick succession to the interaction of a large density of additional microcracks and the development of a large zone of increased shear compliance. 


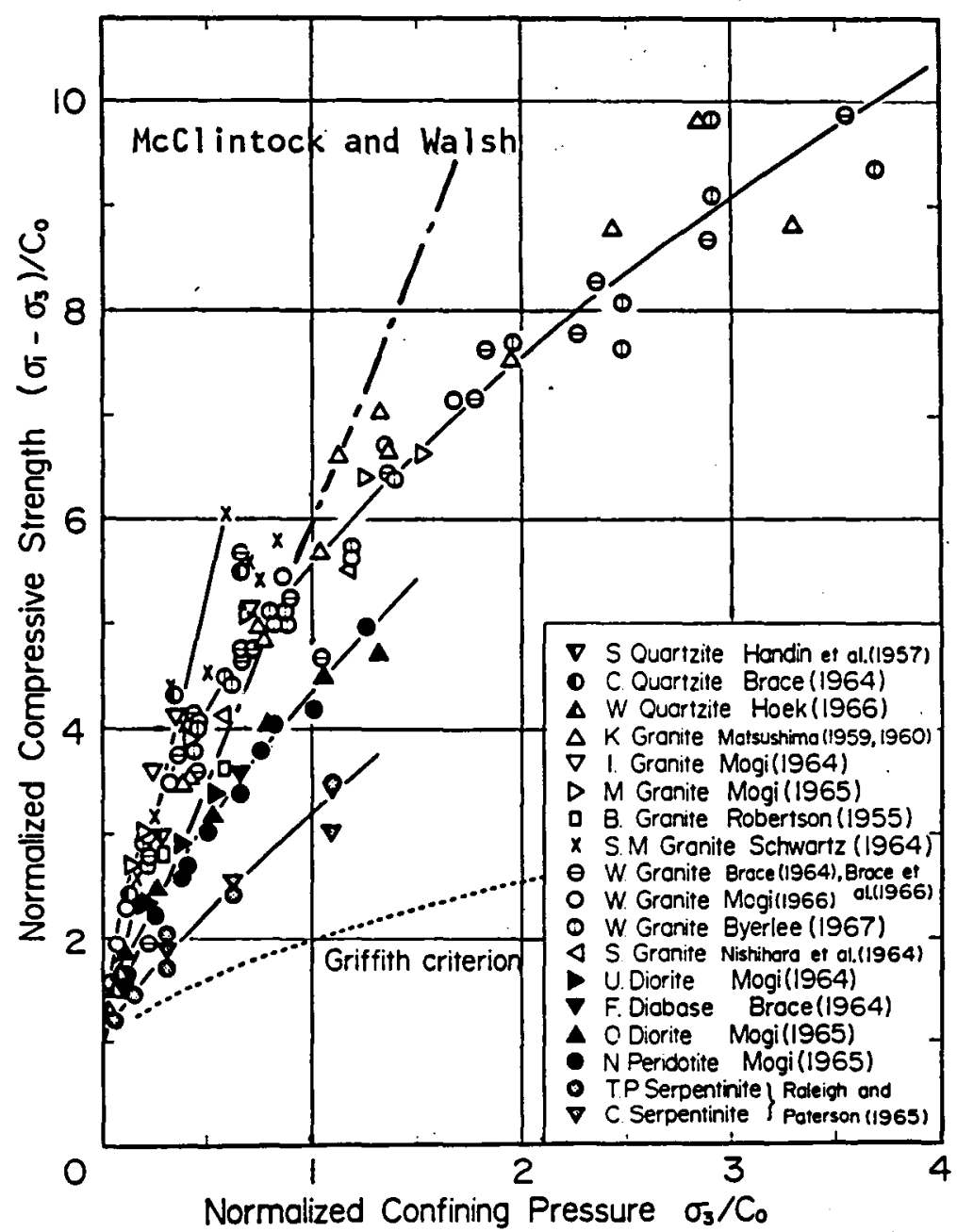

FIGURE 7 Relation between compressive strength and confining pressure for a series of rocks tested at room temperature (Ohnaka 1973). 
EVOLUTION OF SOURCES OF SHEAR FAULTING

Monitoring the evolution of sources of shear faulting by repeated sectioning in incremental stressing experiments is subject to large scatter since each specimen is destroyed in the process of examination. Passive visualization of microcracks by radiography or ultrasonic probing usually does not provide the required resolution and it is difficult to separate the "signal" from the background "noise." On the other hand, monitoring the acoustic emission from the compressed samples by multiple probes permits the determination of the spatial correlation of signals emanating from microcracking events.

Recent technological advancements in acoustic emission (AE) have provided tools possessing sufficient bandwidth and dynamic range to allow studies with considerable spatial discrimination. Early experiments with $\mathrm{AE}$ established similarities between $\mathrm{AE}$ signals in small laboratory compression samples and earthquake activity (Scholz 1968a). Mogi (1972a) demonstrated that different rock types produce different $\mathrm{AE}$ signals. In more detailed studies, Mogi (1968) and Scholz (1968b) began to detect the location of microcracks in a compressed rock sample. Bailey and co-workers (1979), Byerlee and Lockner (1977), Lockner, Walsh and Byerlee (1977), Lockner and Byerlee (1980), Rothman (1977), and Sondergeld and Estey (1981) have attempted to examine the spatial distribution of $\mathrm{AE}$ hypocenters during various stages of compression. The observations of these investigators support the microstructural studies discussed above and show that existing imperfections are likely sites of $\mathrm{AE}$ activity. The microcracking is found to intensify in the neighborhood of the previous sites and is often persistent in a locality until final failure. Component sites of AE activity in a general localization site, however, are found to move around, and once local stress can be relieved, new centers of concentrated activity are observed, indicating the development of more than one final localization nucleus. Acoustic emission occurs in rocks also under pure hydrostatic loading, transverse pressurization, or uniaxial compression with or without transverse pressurization.

Sondergeld and Estey (1982) have studied focal mechanisms of $\mathrm{AE}$ events in some detail. A focal mechanism is characterized by an equivalent set of point forces positioned at the hypocenter of an $\mathrm{AE}$ event consistent with the recorded far field motions. The general finding has been that a microcrack event signature was distinctly not just a dilatational source but more in the nature of a double-couple source consistent with a slipping microcrack. In all cases but particularly under uniaxial compression, clustering of events occurs with strikingly similar focal mechanisms in a cluster as shown in Figure 8. These similarities in the focal mechanisms in a cluster suggest strongly that microcracking is either en echelon and/or in the form of episodic crack extensions in the regions of the clusters.

Spectral analysis of $\mathrm{AE}$ events has been used in the past by many investigators (e.g., Graham and Alers (1974)) and has served to monitor changing processes. Ascribing the changes to specific processes or changes in processes is a difficult but, with some care, not an unsurmountable task. Despite the small dimensions of $\mathrm{AE}$ events, they possess all the character and variability documented in studies of earthquakes. In 

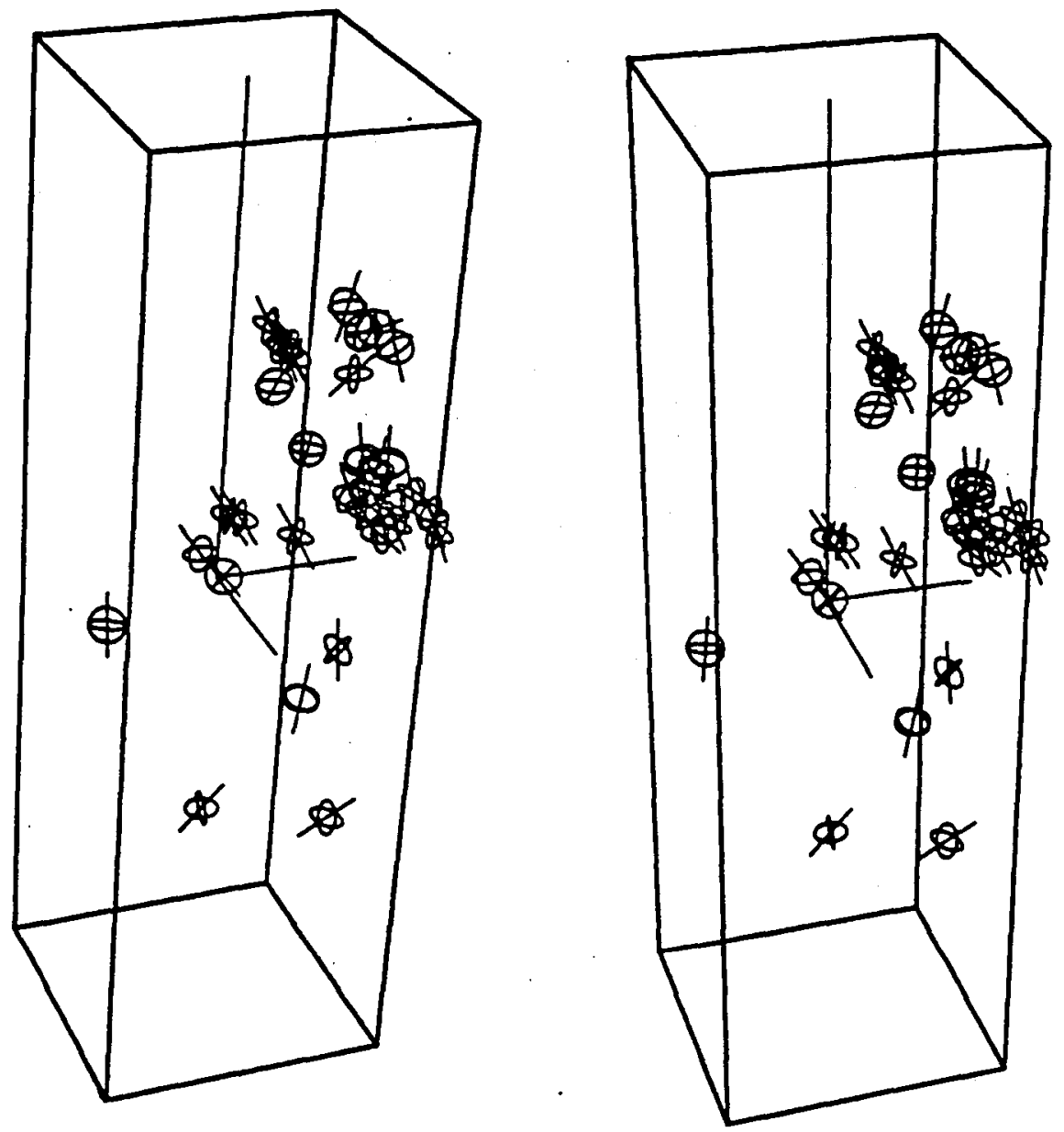

FIGURE 8 Focal mechanisms for acoustic emission events recorded during the uniaxial deformation of Westerly granite. The intersecting circles represent modal planes for P-waves. The orientation of slip planes has been preserved. Note that events which spatially cluster have strikingly similar focal mechanisms (Sondergeld and Estey 1982). 
particular, the events cannot be regarded as point sources since they have length and the failure process is not instantaneous, but rather can be described by a cracking velocity and a rise time. The accuracy of acoustic probing techniques for detection of flaws and monitoring of the development of nuclei of shear localization is discussed in more detail in chapter 8.

\section{DEVELOPMENT OF SHEAR LOCALIZATION}

There have been no definitive experiments carried out on brittle substances with microstructure in which the conditions of shear faulting and angles of shear faults have been measured and compared with theory. In view of this, the corresponding process of shear localization in dilatant plastic solids with a pressure dependence of the plastic resistance will be examined. Even though no fracture usually results from such shear localization the stress conditions and other general features of the process are expected to be qualitatively identical to shear faulting in brittle solids.

Anand and Spitzig (1980, 1982) have conducted the most careful comparisons of theory and experimental observations on the emergence of shear bands. They investigated three materials: a high-strength maraging steel; the polymer, polystyrene; and a soil, Leighton Buzzard sand. Inelastic dilatation is neglected in the steel and the polymer but not the sand. There is a small but unimportant pressure sensitivity of yield in the case of the steel, but an important pressure dependency is accounted for in calculating the bifurcation condition for the other two materials. Tests were carried out in plane strain compression with data for the sand coming from tests by Arthur and co-workers (1977). For each material the strain at which shear bands first set in was ascertained and the angle made by the band with the compression axis was noted. In the case of steel, the onset of the shear bands did not result in any dramatic change in the load-deflection behavior of the specimen. However, the specimens of the other two materials displayed a peak in the overall load-deflection curve at or shortly after the shear bands first emerged and from that point onward overall strain softening occurred.

Anand and Spitzig (1982) specialized the bifurcation condition of Rudnicki and Rice (1975) to plane strain compression. In general, the incremental moduli for this restricted class of deformations involves four history-dependent material parameters: the dilatancy parameter $\beta$, giving the rate of dilatation with shear; the pressure sensitivity parameter $\mu$, giving the rate of rise of the plastic shear resistance with pressure; the tangent modulus $\mathrm{E}_{t}$, governing $\mathrm{plane}$ strain compressive increments; and the incremental shear modulus $G_{t}$ for shearing at 45 degrees to the compression axis. For the steel the value assigned to $G_{t}$ was of crucial importance in the theoretical prediction. Anand and Spitzig (1982) used the measured critical stress at the onset of banding together with the theoretical formula for this stress to infer the value of $G_{t}$. They found a value that was below even what a deformation theory would predict and, thus, probably unrealistically low. Furthermore, the measured strain at the onset of banding was below that predicted theoretically. It is quite likely that a strong imperfection sensitivity to initial material inhomogeneities may explain both discrepancies (Hutchinson and Tvergaard 1981). 
For the polystyrene and the soil the incremental shear moduli played a less crucial role in the theoretical results, and the emphasis in the comparison with experimental observations was on the angle of inclination of the bands to the compression axis. For all three materials the theoretical predictions for this angle were in rather good agreement with that observed experimentally.

There have been no corresponding laboratory experiments on the faulting localization of brittle rocks or concrete to compare with the predictions of the theory of Rudnicki and Rice (1975). On the other hand, microstructural aspects of the initiation of the microcracking process among grains in rock samples, leading to clustering of such cracks and establishment of a nucleus for shear localization, have been investigated qualitatively in great detail and have been related to the features of the compression stress-strain curve. (These observations will be discussed in chapter 5.)

\section{EFFECTIVE TOUGHNESS IN SHEAR FAULT PROPAGATION}

As discussed above, the sigmoidal extension of individual microcracks is a Mode I fracture problem, albeit on a microscopic scale where, however, the critical factor is the Mode I fracture toughness $K_{I C}$. When compressive fracture results from the development of a shear fault (initiated by the en echelon action of many microcracks followed by fragmentation, etc.), however, much larger amounts of energy dissipation become necessary and the effective fracture energy $G$ can be expected to be of a much larger magnitude. Wong (1982c) has estimated the shear fracture energy of Westerly granite from post-failure deformation behavior and has found it to be in the range of $2-5 \cdot 10^{4} \mathrm{~J} / \mathrm{m}^{2}$. This figure compared well with earlier measurements on similar rock but was from 1 to several orders of magnitude lower than other estimates based on seismic data and the like. The corresponding fracture energies for Mode I loading obtained by Brace and Walsh (1962) and Atkinson (1979), on the other hand, range only between 1 and $10^{2} \mathrm{~J} / \mathrm{m}^{2}$. This confirms the expectation and indicates clearly that information obtained from Mode I fracture energy measurements has little predictive value for the case of compressive fracture involving shear faulting. 
COMPRESS IVE FRACTURE IN ROCKS

\section{PHENOMENOLOGY AND MECHANISMS OF ROCK FRACTURE}

\section{Introduction}

An understanding of rock fracture is of fundamental importance to several branches of engineering and earth science. Specific examples are: (1) the avoidance of failure in underground excavation for mining, energy storage caverns, and nuclear waste isolation; (2) the analysis of slope instability in dams, in transportation of rocks, quarry and mine pits; (3) the evaluation of cutability or durability of rocks and the design of cutting and drilling tools; and (4) hydraulic fracturing for recovery of oil, gas, and geothermal energy. The strains involved in such applications are relatively small; therefore, one is principally concerned with the brittle behavior of rock. In the earth sciences, an understanding of brit.te fracture is crucial to the geologic faulting problem. There are also a variety of geologic phenomena (e.g., mantle convection and folding of stratified rock), the interpretation of which hinges on an understanding of the ductile and semi-brittle behavior of rocks.

A wide spectrum of loading configurations are encountered in both engineering practice and tectonic processes. Failure in either a tensile or a shear mode is possible. Examples of the former include flexure of a mine roof, hydraulic fracturing, and magmatic intrusion. Owing to the dominant. influence of gravitational overburden, the principal stresses in rock masses are frequently all compressive. In this latter case, shear fracture occurs when the deviatoric stresses have become critical. A "fault" is formed (by clustering of microcracking processes) with simultaneous release of stress by relative slip on the shear band.

One of two approaches usually is taken in the study of compressive fracture in rock and both have contributed significant.ly to current understanding. The first is an "applied mechanics" approach commonly 
used for engineering design and qualitative analysis of geologic faulting. The fracture process is taken as a discrete event without significant prior deformation and without warning. The only physical quantity of interest is the peak stress, which is of interest as an upper bound on solutions of boundary value problems. Fundamentals of this approach are covered by Goodman (1980), Hoek and Brown (1980), and Jaeger and Cook (1979). A recent report by the National Research Council's U.S. National Committee for Kock Mechanics (1981) also touches on this subject. The second approach is a "materials science" one that supplements standard deformation tests with NDE and microscopy, aiming at a fundamental understanding of the microscopic mechanism. The evolution of microstructure is treated as a continuous process culminating in the coalescence of microfissures to form a thorough-going fault. Such an approach was adopted by Paterson (1978) in his extensive review of rock fracture.

\section{Background}

Kock is undoubtedly one of the materials for which fracture behavior under compressive stresses has been studied most thoroughly. In comparison with other materials such as metals or ceramics, rocks have several distinctive characteristics:

1. The term "rock" includes a great variety of material types. Granite can behave in a brittle manner up to a confining pressure of 1 GPa whereas carbonate rocks become plastic at moderate pressures of about $100 \mathrm{MPa}$. Extensive crystal plasticity is observed in rock salt at moderate stress under room temperature whereas most quartz-bearing rocks do not show significant dislocation activities up to a temperature of $400^{\circ} \mathrm{C}$.

2. Even in a virgin state, rocks are permeated with pores and microcavities that were formed during the inception of the rock and are related to brittle fracture during geological motions in early times. The porosity and microcavity morphology are as important-or even more vital with regard to rock properties--as the mineralogic composition itself. Collectively the microcavities cause a nonlinear dependence of strain, uitrasonic velocities and attenuation coefficients on stress, a strong pressure dependence of fracture strength, a variability and scatter in test results, and probably a scale effect into the prediction of mechanical behavior.

3. Rock has a finite hydraulic conductivity, which implies that the void space forms an interconnected network. There is petrological and geophysical evidence that rocks possibly are saturated with water to a depth of tens of kilometers. Pore fluid also plays a significant role in engineering applications for energy resource recovery or dam construction. The effect of pore fluid on fracture behavior can be either mechanical through pore pressure diffusion or chemical through stress corrosion.

\section{Experimental Technique}

The conventional triaxial test of jacketed cylindrical specimens (compressed axially under transverse pressure) was pioneered by von Karman (1911) and is by far the most popular technique for laboratory measurement of temperature- 
dependent mechanical behavior of rock. Nearly all such apparatus for rock mechanics operate within the $1 \mathrm{GPa}$ pressure range, and, even within this range, most have been restricted to pressures of between 300 and $500 \mathrm{MPa}$. The adaptation of triaxial apparatus for use at elevated temperatures is relevant mainly to studies in the ductile field, but there recently have been at least two studies on brittle fracture at temperatures up to about $700^{\circ} \mathrm{C}$ (Friedman et al. 1979, Wong 1982a).

No information on the effect of the intermediate principal stress is furnished by the conventional triaxial test, but Mogi (1972a) performed a thorough investigation of this effect by "true" triaxial testing on cubic samples. A limited amount of data from torsional testing also were reported by Handin and co-workers (1960 and 1967).

Most of the rock strength data available are on centimeter-size cylindrical samples. In one exceptional study Singh and Huck (1973) performed triaxial tests in a laboratory cell on granite and limestone cylinders up to 0.9 in. diameter. Several laboratories, however, currently are developing large-scale testing facilities (National Science Foundation 1981). Nevertheless, most of the truly large-scale tests are performed in the field. A systematic in-situ investigation of the size effect was made in South Africa by Bieniawski and van Herdeen (1975), to help design the pillars in coal mines. Pratt and co-workers (1972) performed laboratory and in-situ tests on quartz diorite with specimen dimensions of up to $3 \mathrm{~m}$.

\section{The Effect of Confining Pressure and Temperature on Strength}

Because of its fissured state, the brittle strength of most rocks shows a strong pressure dependence. It is not uncommon to achieve a tenfold increase in strength by a small increment in mean stress, as is shown in Figure 7. As we discussed earlier in chapter 3, depending on the signs of the principal stresses, a sample can fail in tension or in shear. Here however, only shear fracture that occurs when the principal stresses are all compressive (Figure 9) is considered. The fracture angle is defined to be the angle between the shear faulting surface and the maximum principal compressive stress $\sigma_{1}$.

Most of the empirical fracture criteria discussed earlier are formulated from conventional triaxial test data with the implicit assumption of the independence of the phenomenon on the intermediate principal stress $\sigma_{2}$. Mogi (1972a), however, concluded from his "true" triaxial tests on cubic samples that this is only an approximation. He found that when the minimum compressive stress $\sigma_{3}$ is kept constant, an increase in $\sigma_{2}$ results in an increase of $\sigma_{1}$ at failure (Figure 10a) and, furthermore, that the fracture angle decreases with increasing $\sigma_{2}$ when $\sigma_{3}$ is fixed (Figure 10b). The fracture surface, however, always contains the $\sigma_{2}$ direction. Ductility also is found to decrease with an increase in $\sigma_{2} \cdot$ similar conclusions were drawn by Handin and co-workers (1960 and 1967) from torsion tests on hollow cylindrical specimens.

The effect of a temperature increase is to decrease the fracture stress (Friedman et al. 1979) and to stabilize the post-failure behavior (Wong 1982a). In general, in comparison with pressure, temperature has a relatively small effect on the brittle fracture of dry rocks. 


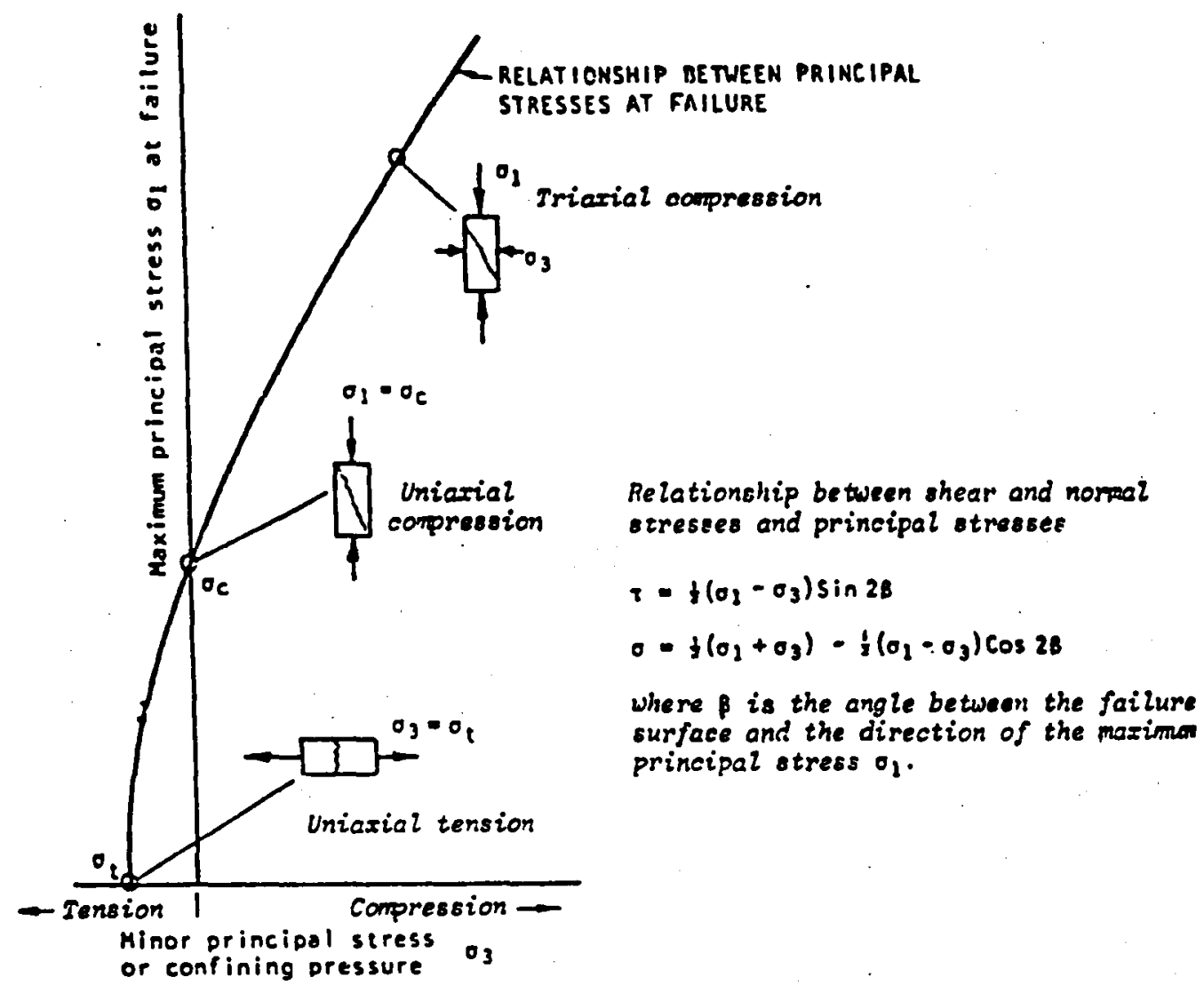

FIGURE 9 Relationship between shear and normal stresses and principal stresses at failure ranging from tensile to uniaxial compression to compression under a confining pressure (Hoek and Brown 1980). 


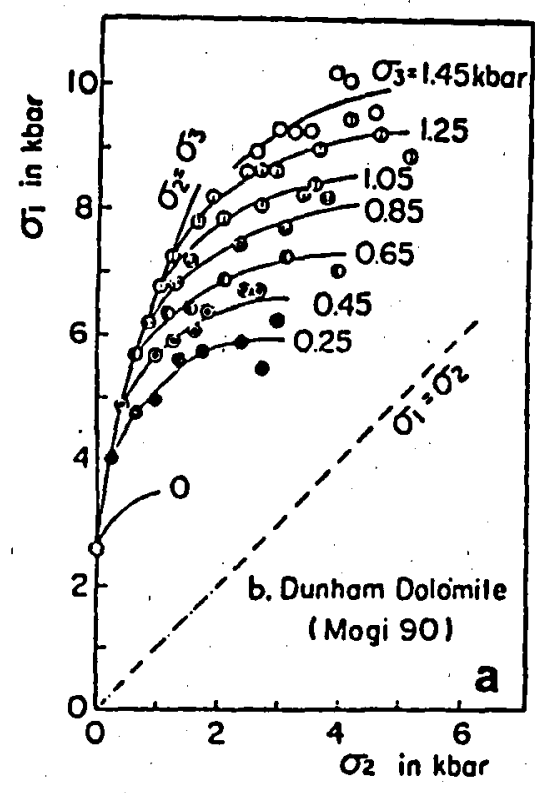

(a)

\section{Frocfure Angle}

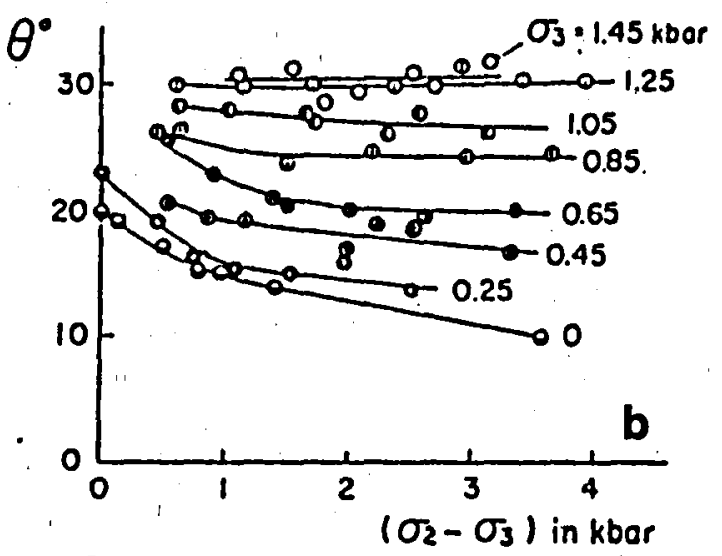

(b)

FIGURE 10 The dependence of the compressive strength $\sigma_{1}$ on transverse compressive stress $\sigma_{2}$ for different levels of the third principal compressive stress $\sigma_{3}\left(<\sigma_{2}\right)(a)$, and the dependence of the fracture angle $\theta$ between the shear fault plane and the direction of principal compression, on the principal stress difference (b), from tests in triaxial compression (Mogi 1972b). 
The Effect of Pore Fluid

Experiments on sedimentary rocks by Handin and co-workers (1963) and on crystalline rocks by Brace and Martin (1968) show that if the sample is "drained," Terzaghi's principle of effective stress should apply to fracture (Jaeger and Cook 1979). If pore fluid diffusion is relatively slow (i.e., so that pore pressure is no longer uniform), it is necessary to take into account the microcavity deformation and permeability. Theories for such so-called poroelastic behavior have been developed primarily in petroleum engineering (Biot 1941) and have been reviewed by Rice and cleary (1976).

If the interstitial fluid is not inert relative to the mineral constituents of the rock, the pore fluid can exert a chemical effect in addition to the purely mechanical one discussed above. An evident weakening effect in water-saturated samples has been observed in calcite by Rutter (1972) and in quartz by Scholz $(1968 \mathrm{c})$. The observed behavior is usually attributed to stress corrosion cracking (Atkinson 1982). Mizutani and co-workers (1977) investigated the strengthening effect of a sample when placed in a high vacuum similar to the lunar environment (Figure 11). A limited amount of available data indicate that the stress corrosion cracking effect is reduced by an increase in pressure (Kranz 1980) or a decrease in temperature (Kranz et al. 1982).

The Effect of Size

The size effect in fracture is of particular importance in rock mechanics because of the large span in dimension between laboratory specimens and rock masses involved in engineering practice. The effect for uniaxial

compression has been investigated to some extent. Figure 12 is a summary of published data on several relatively weak rocks tested in-situ. The ratio of field to laboratory strengths can be as high as 10 as the size of the samples correspondingly decreases. The available data indicate that there is a critical size of about $1 \mathrm{~m}$ above which there is no further decrease in strength. This, however, was likely affected by the difficulty of carrying out tests on samples of larger dimensions, and by the usual careful selection procedure of the samples that were actually tested.

Because of the lack of data on larger samples of hard rocks, a similar minimum strength has not been demonstrated (Brace 1981). In fact, Hodgson and Cook (1970) concluded from their tests on a hard competent rock that no size effect is evident. It also often has been suggested that size effects should be less at a higher confining pressure (Paterson 1978), but this idea is essentially untested.

One approach to interpret the size effect is to adopt a weakest 1 ink model, a variant of Weibull's theory (Weibull 1.939) which assumes that fracture of a sample occurs when the weakest element fails or the worst crack grows. As already discussed in chapter 3 , the "intrinsic" compressive strength of rocks involves the growth and coalescence of many cracks to a fault nucleus that then spreads. On the other hand, in rocks that contain an uncharacteristically large extrinsic precrack, a shear fault can be initiated from it earlier, short-circuiting the evolutionary nucleus formation process. On this basis, no important size effect is expected in 


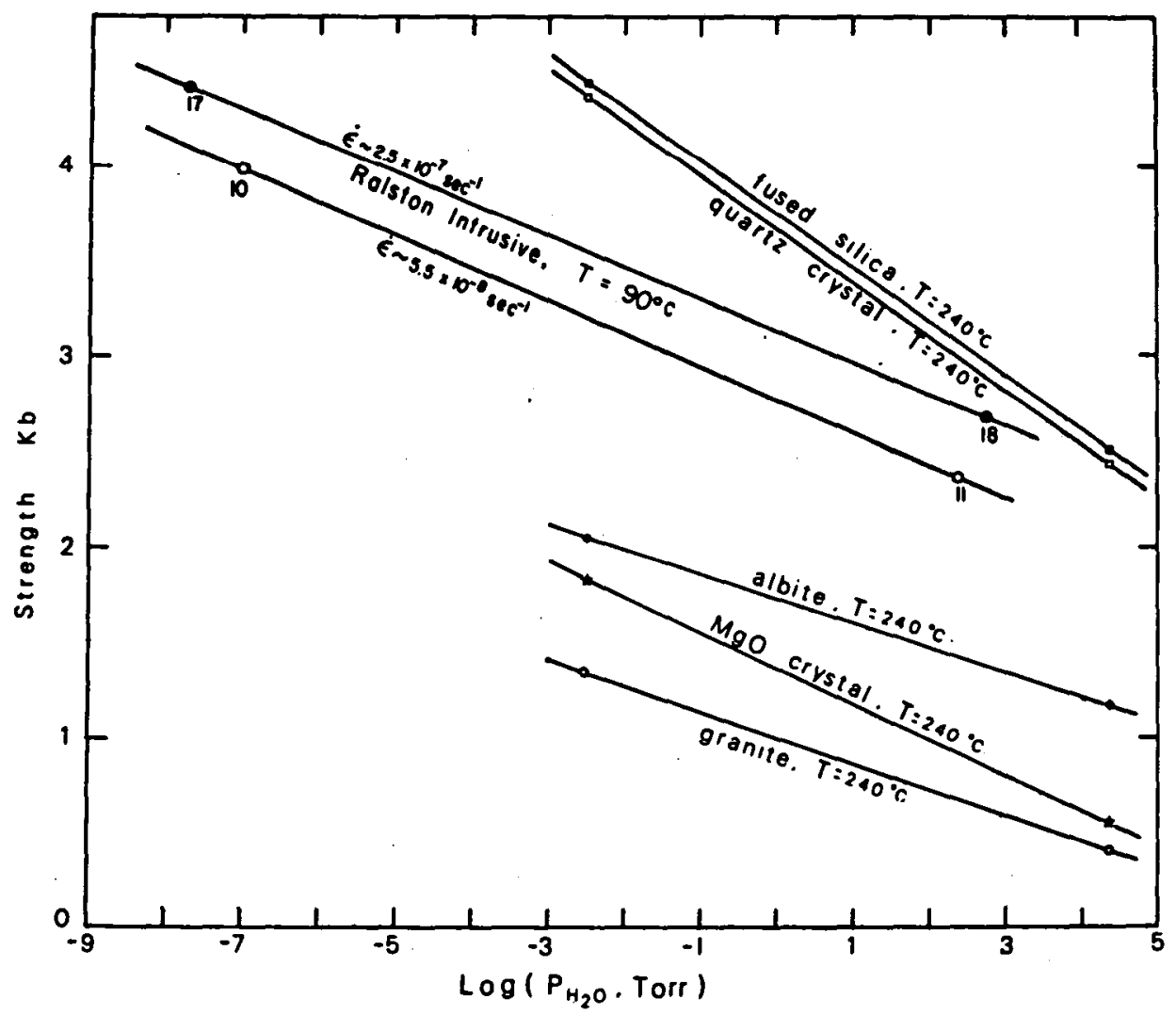

FIGURE 11 Dependence of compressive strength on the vapor pressure of water in an isolation chamber; the actual pressure felt by the growing crack is likely to be considerably higher (Mizutani et al. 1977). 


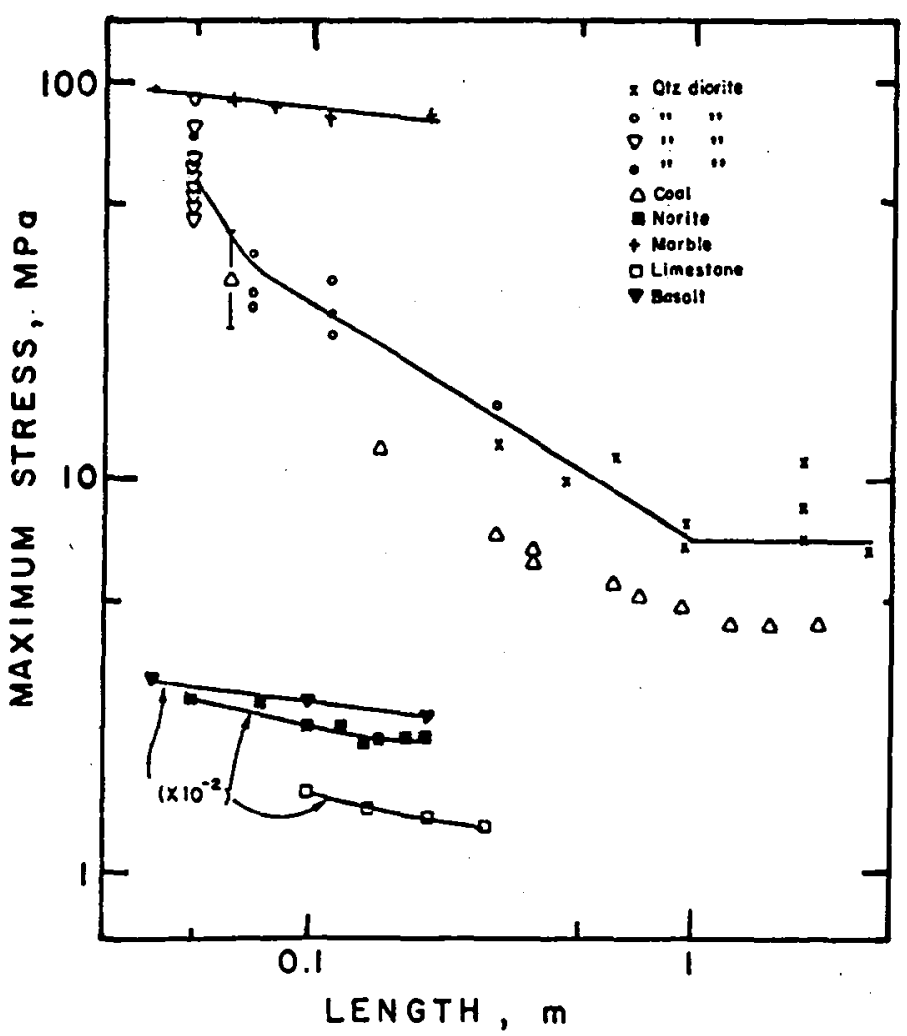

FIGURE 12 Dependence of compressive strength of rocks on size (Brace 1981).

rocks containing a narrow distribution of precrack lengths when they are tested on a scale much larger than these cracks but a size effect is expected in rocks containing a family of extrinsic precracks much larger in size than the microstructural scale when they are tested on a scale within the size range of these extrinsic cracks.

The Micromechanics of Faulting

Active research in the past two decades has deepened understanding of the inelastic deformation processes leading to the formation of a terminal shear fault. A brittle rock tested in triaxial compression will show dilatancy when the differential stress $\left(\sigma_{1}-\sigma_{3}\right)$ reaches one-third to one-half the peak value. Usually dilatancy and pressure dependence of the fracture stress go together. The pressure dependence becomes very small only when dilatancy disappears (Brace 1978). Significant increase in void density is due principally to inelastic strain in the radial direction, which Brace and co-workers (1966) have attributed to stress-induced microcracks extending parallel to $\sigma_{1}$. Other physical measurements including shear wave birefringence (Bonner 1974), attenuation (Lockner et al. 1977), electrical resistivity (Brace and Orange 1968), and permeability (Zoback and Byerlee 1975) have corroborated this interpretation. Scholz (1968d) demonstrated that acoustic emission activity sharply increases with the onset of dilatancy. Mogi (1978) concluded from his strain measurements in "true" triaxial tests that the inelastic dilatation is largest in a direction parallel to the least principal compressive stress $\sigma_{3}$, as can be expected from the microcrack extension models. 
Soga and co-workers (1978) performed measurements on an initially isotropic rock stressed in a pressure vessel with a window for holographic interferometry. The three-dimensional strain measurements indicated a gradual evolution of homogeneous, transversely isotropic deformation culminating in shear localization as the differential stress reach its peak value. Similar conclusions also were reached by Lockner and Byerlee (1980) and Sondergeld and Estey (1981) on the basis of the clustering of acoustic emission sources (as al ready discussed in chapter 4).

\section{Direct Observation of the Damage Microstructures}

Progress in the direct observation of microcavities and microcracks in rock has been hampered by the difficulty of differentiating between the original microcavities and the artifacts introduced during the preparation of the thin sections. Brace and co-workers (1972) suggested that the artifacts can be minimized by a surface preparation procedure with ion-milling as the final step and that the fine details can be resolved under the scanning electron microscope (SEM) down to a scale of $10^{-2} \mu \mathrm{m}$. Extensive SEM studies since then on rock types such as granite, gabbro, diabase, quartzite, and sandstone have provided a detailed picture of microcavity morphology (Richter and Simmons 1977). It suffices for the discussion of mechanical behavior to separate the microcavities into two categories: the almost equidimensional pores and the lenticular, slot-1ike cracks. As already touched on briefly above, a thorough SEM study by Hadley (1976) showed that in a virgin granite, the pores of aspect ratio (ratio of opening to length) 0.1 to 1 are generally with dimensions less than $5 \mu \mathrm{m}$ and that the crcks typically have aspect ratios of $10^{-4}$ to $10^{-2}$ and lengths less than $100 \mu \mathrm{m}$, which is about one-tenth the grain size.

\section{Development of Stress-Induced Microcracks and Shear Localization}

Recent SEM studies (Batzle et al. 1980, Kranz 1979, Tapponnier and Brace 1976, Wong 1982b) have provided a good picture of the micromechanics of dilatancy. Except for the recent work by Batzle and co-workers (1980), which was performed in-situ under uniaxial compression, most studies considering more complex stress fields are on samples retrieved from the pressure vessel after being subjected to stress. Microstructural changes also can be caused by pressure and temperature cycles (Sprunt and Brace 1974), but they are minor relative to those induced by compression. Unlike those in the virgin samples, the stress-induced cracks tend to be sharp-tipped and relatively straight. They have the strongly preferred orientation suggested by other physical measurements discussed above, and most of them are transgranular, seldom crossing over grain boundaries.

Tapponnier and Brace (1976) concluded that dilatancy is primarily a consequence of two types of cracking: the widening and extension of pre-existing discontinuities (e.g., grain boundaries, cracks, and pores) and the initiation and propagation of cracks at sites with high contrast in elastic moduli (e.g., at transverse grain boundaries between different minerals).

A conclusion common to all the SEM studies is that the stress-induced cracks are in general a result of Mode $I$ growth in tension, as would be 
expected from the microcrack extension models driven by the shear offset of pre-existing cracks. The compression-induced crack orientation has a highly anisotropic distribution and is mostly at low angles (i.e., less than 15 degrees) to $\sigma_{1}$, although Wong (1982b) has reported a number of cracks inclined at higher angles to $\sigma_{1}$ in granite samples deformed under pressure and higher temperature than in previous work. There have been no reports of appreciable Mode II or III growth of pre-existent microcracks in the samples prior to the onset of a shear fault.

A continuum description of the mechanical behavior of a complicated, polycrystalline material such as rock probably is adequate only over a continuum element large enough for the effects of grain scale inhomogeneity and anisotropy to average out. The SEM observations show that the mineral quartz, comprising about one-third by volume of the granite, has limited participation in the localization process in the initial post-failure stage. In other words, localized deformation extending over a continuum element with grains of all major mineral types is not observed until the sample has been deformed well into the post-failure stage. In this limiting sense, the SEM observations agree with the theoretical predication of the localization analysis outlined in chapter 3 for frictional, dilatant materials. Such analyses (e.g., Rudnicki and Rice 1975, Rudnicki 1977) predict that the onset of localization under axisymmetric compression should occur when the sample has been deformed well into the strain-softening stage.

\section{APPLIED PROBLEMS IN COMPRESSIVE FRACTURE OF ROCKS}

\section{Introduction}

One of the most important practical applications of fracture of brittle solids in compression is the penetration of tools into rock. Specific examples include percussive and rotary drilling, drag bit drilling, and ploughing or planing of rock formations (e.g., coal). In spite of the extreme commercial importance of tool penetration into brittle rock, details of the penetration mechanism still are poorly understood. Much of the past. work in this area has been directed toward semi-empirical drilling models often specific to a particular formation. Although such models have engineering utility, they generally are not consistent with recent developments concerning the constitutive behavior of rock and are not based on the mechanistic processes described above. Hence, their range of applicability is quite limited. Here, current practice in phenomenological theories for tool penetration into rock and attempts at developing mechanistic models for chip formation will be reviewed.

Quasistatic tool penetration tests (Hartman 1959, Evans and Murrell 1958, Singh and Johnson 1967, Reichmuth 1963, Sikarskie 1966) have established the features of the penetration mechanism. Figure 13 represents a typical set of force-penetration traces of wedge-shaped tools into charcoal grey granite. As the traces suggest, the process occurs in a repetition of two distinct phases. The first is a crushing phase in which the forces on the tool increase monotonically. Hydrostatic stresses in the 
vicinity of the tool tip are extremely high and the material under the tip essentially is crushed in the region of very high contact pressures. The crushed material behaves in an almost plastic fashion. Stresses are transmitted through the crushed zone to the virgin material below. As these stresses in the surrounding material increase, a macrofracture zone is initiated and, with subsequent load increase, eventually grows to form a chip under decreasing tool force to complete one discrete step. The cycles now repeat. under increasing total force as the contact area between the tool and the rock increases. A typical drilling situation may see 2 to 4 such cycles per blow. The cyclic behavior also is observed in drag bits (Whittaker and Szwilskie 1973). This above cyclic penetration behavior applies to rock at low confining pressures. At high confining pressures (e.g., in deep drilling), rock becomes outwardly more ductile with smooth, monotonic force-penetration curves (Cheatham and Sikarskie 1973).

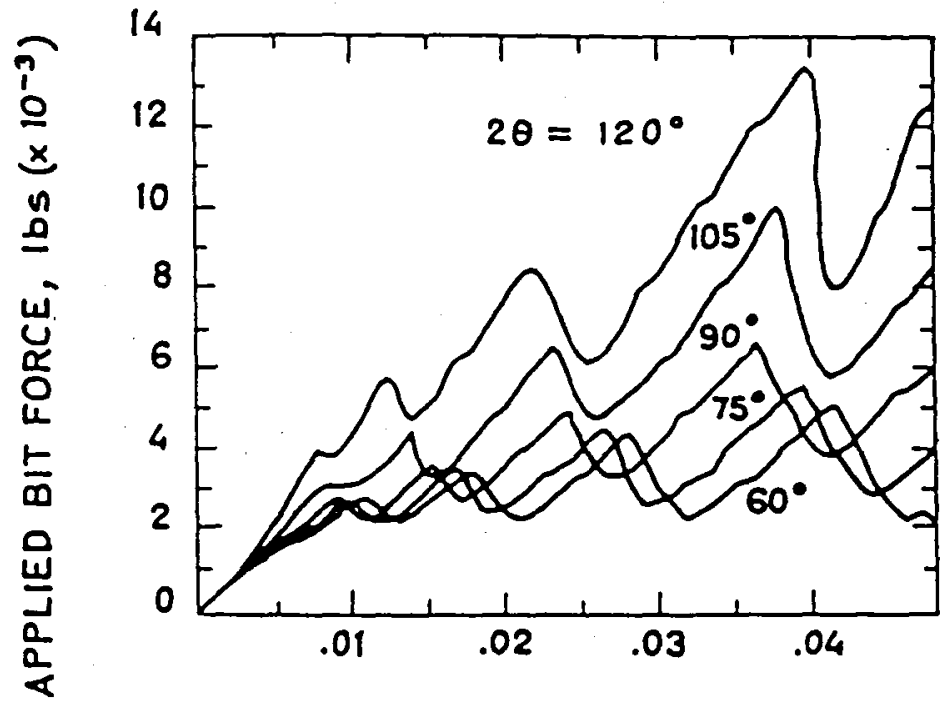

BIT PENETRATION, INCHES

FIGURE 13 Characteristic force-penetration curves for charcoal grey granite by $2.5 \mathrm{~cm}$ wide wedges (Reichmuth 1963).

\section{General Theoretical Models for the Faulting "Plasticity" of Rocks}

The process of chip formation in rock machining as outlined above involves the repeated application of local shear faulting in the rock under the concentrated pressure of the tool. The mechanics and mechanisms of the evolution of microcracking processes leading to the formation of a shear fault nucleus in a homogeneous compressive stress field under confining pressure applies locally in the rock that is to be chipped, albeit in this case the local stress field is highly inhomogeneous and the shear faults 
make up curved surfaces. In such situations more formal phenomenological theories clearly are called for to deal with the problem on the basis of a continuum without repeatedly coming to grips with the details of faulting. The constitutive localization model of Rudnicki and Rice (1975) that develops conditions of shear localization by treating the brittle rock undergoing microcracking as if it were a pressure sensitive, somewhat dilating plastic continuum serves as a guide. This suggests that problems of this type should be amenable to analysis by the slip line field method of the mathematical theory of plane plasticity, generalized to deal with plastic continua exhibiting pressure dependence of the plastic resistance and dilatancy and including, if necessary, vertex phenomena on yield surfaces that are known to make the material more prone to localization of deformation. A number of attempts have been made to model the behavior of granular materials such as soils (Drucker and Prager 1952, Szczepinski 1971, Drescher et al. 1967, Mroz and Szymanski 1979, Spencer 1982, Anand 1982). These have been applied with varying degrees of success in inhomogeneous problems such as indentation of a half space of sand or soil but have not found application to corresponding problems of machining or chip formation in rocks.

\section{Specific Models for Chip Formation}

Some particular theoretical models following slip line plasticity approaches have been developed specifically for the purpose of dealing with chip formation in rocks by the wedge indentation process. Figure 14 shows a schematic two-dimensional view of a wedge penetration model developed by

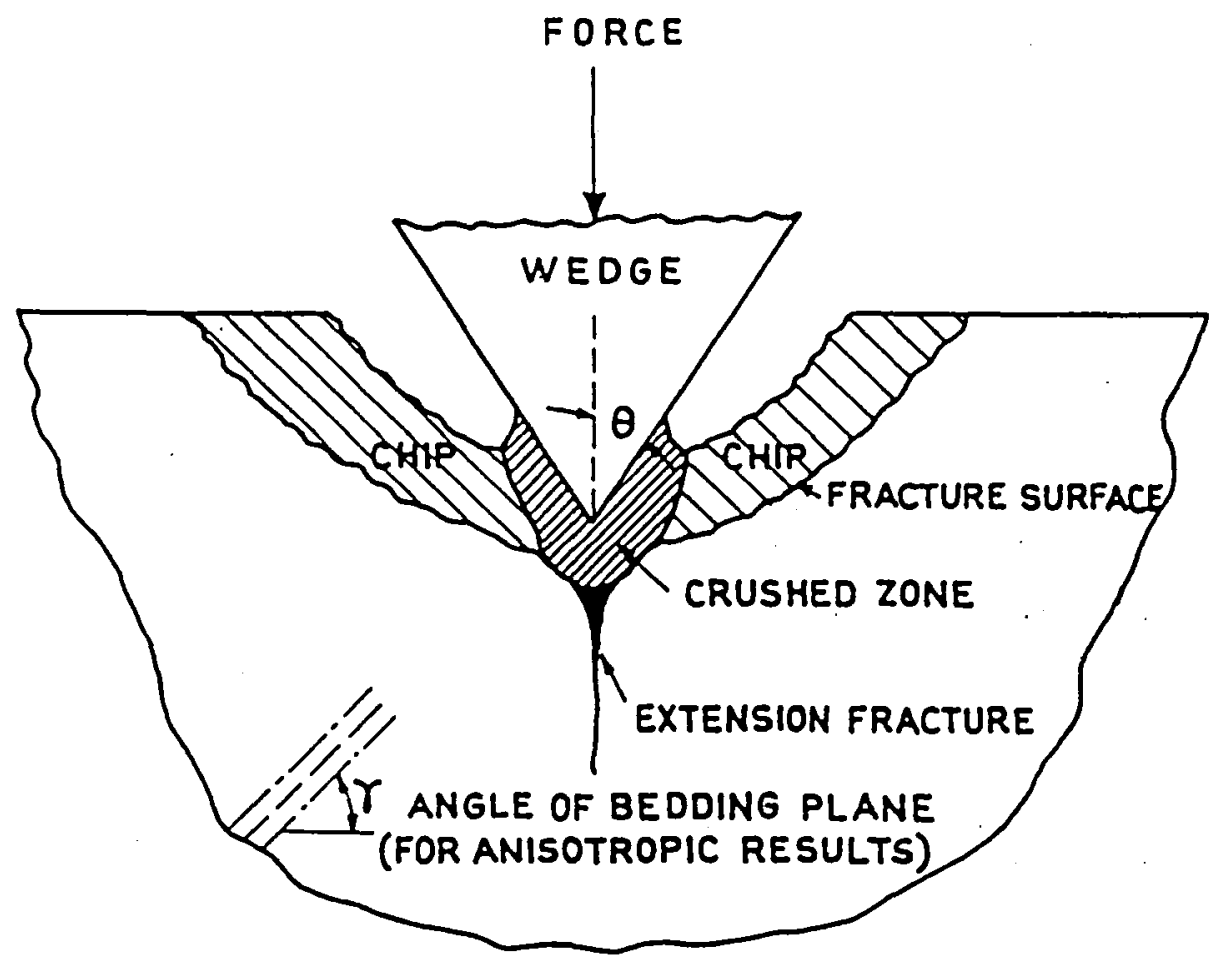

FIGURE 14 Idealized model of the penetration of a tool wedge into rock. 
Paul and Sikarskie (1965). The plane strain model has assumed symmetrical distortions and an initial local penetration by crushing that is linear with the applied force. It assumes further that the chips are planar blocks and that they move out of the way when the Coulomb-Mohr criterion of a pressuredependent plastic resistance can be counteracted. The model demonstrates that for proper chip formation the wedge angle $\theta$ shown in Figure 14 must be less than a given amount, determined by the friction angle between wedge and rock and the pressure dependence of the plastic resistance that governs the Coulomb-Mohr criterion. The model is capable of presenting an upper bound outer envelope to the force-penetration behavior of a wedge as given in Figure 13. The model has been extended to the symmetrical penetration of anisotropic rock by Benjumea and Sikarskie (1969) and to tilted application of the wedge by McLamore (1971).

The simple wedge penetration model described above is not fully consistent with the actual phenomenon. Altiero and Sikarskie (1974) have studied this in some detail on models made of plaster of Paris to better understand the complex processes of vertical splitting (extension fracture), crushing, and chip formation in the brittle substance. On the basis of their observations Sikarskie and Altiero (1973) analyzed the wedge penetration process as a quarter space loading problem where the free surface and the vertical splitting delineate the quarter space boundaries as shown in Figure 14. The normal and frictional loading of the interface between the rock and the wedge then is considered in detail, the stress distribution in the rock is calculated, and the Coulomb-Mohr criterion is applied to determine the point where the fracturing will begin. The growth direction of the chip was assumed to follow along the steepest slope of the Coulomb-Mohr function. This clearly is somewhat arbitrary and instead the generalized slip line field approach discussed above should have been used.

\section{Other Applications of Kock Fracture}

There are many other applications of rock fracturing of industrial interest. The problem of hydraulic fracturing of great interest in improvement of oil recovery from oil-bearing rock beds is primarily a problem of tensile fracturing of rock under a large well-bore pressure and the opposing confining pressures of the surrounding rock albeit made complicated by the flow processes of pore fluids. This and other similar fracturing problems are outside the scope of this report. Problems of mine shaft failures and lateral displacement of large earth works such as dams and embankments are direct applications of compressive fracturing of rock and soil flow, both obeying the general framework of shear faulting theories referred to above and to be discussed further in chapter 6 . The framework for the solution of such problems thus exists and some already have been solved while others still await solution. 
- 
COMPRESSIVE FRACTURE IN CONCRETE, CEMENTED CARBIDES AND

ULTKA-HIGH STRENGTH METALS

FRACTURE IN CONCRETE

General Background

Without doubt, concrete is the technologically most important brittle material. Its importance in stationary structural applications is perhaps overshadowed only by steel with which it competes and on which it often relies for improved overall properties. In spite of its widespread use and large amounts of engineering research and development to make its properties reproducible, the microstructure and behavior of concrete is still inadequately understood. Although basic concrete consists of Portland cement, water, and aggregates that are widely available, the making of concrete with superior properties requires adherence to strict procedure. For a general treatment of the properties of concrete, its ingredients, the procedure for its preparation, and its use, the reader is referred to standard treatises such as that of Neville (1975). The status of research on cement and concrete in the United States has been reviewed recently by the National Research Council (1980). Only the problem of the compressive strength of unreinforced concrete will be considered here.

Phenomenology of the Compressive Strength of Concrete

It has now been well established that the strength of a properly prepared concrete will continue to rise with curing time at room temperature. This rise in strength continues with decreasing rate over a period of years. The most rapid change in strength is limited, however, to the first 90 days. Because of this, it is general practice in evaluating the properties of concrete to rely on standardized tests on samples with 7 day cure or 28 day cure; in typical cases the latter strength is expected to be 50 percent higher than the former. 
The development of porosity and microcracking due to differential shrinkage during cure makes concrete an unreliable material in tension and necessitates its reinforcement with steel in structural applications where the steel is expected to impart tensile strength. In usual practice, a tensile strength of no more than 4 to $5 \mathrm{MPa}$ can be expected. In parallel with the general expectation concerning brittle solids the uniaxial compressive strength of concrete is 6 to 8 times higher than its tensile strength. Under a lateral confining pressure, however, the compressive strength of concrete increases dramatically, as shown in Figure 15. A corresponding increase in strength also is observed in the compressive strength of neat cement and mortar, indicating that the strength-reducing microcracks and fissures are present even without aggregates. In Figure 16 data on the dependence of the compressive strength of concrete on a lateral pressure are plotted, normalized with the uniaxial compressive strength and with the lateral pressure being normalized in the same way (Lowe 1979). Comparison of Figure 16 with Figure 7 for rocks shows the similarity of the fracture behavior of concrete and of rock. Further, in this instance, too, the biaxial fracture theory of Griffith as modified by McClintock and Walsh to account for crack face friction gives a good basis for a scaling law.

Detailed experiments on the phenomena that accompany the eventual fracturing of concrete in compression have indicated that, as with rock, the precursor phenomena of microcracking across the direction of smallest compressive stress and into the direction of principal compression begins at around 50 to 75 percent of the ultimate compressive instability stress. The beginnings of these microcracking events have been studied with both measurement of the velocity of sound in the transverse direction and with ultrasonic pulse echo techniques (Neville 1975). These investigations have shown that such stable microcracking occurs earlier in concrete with coarse aggregate gravel having smooth surfaces than in cements employing aggregate in the form of crushed rock with jagged surfaces. The use of aggregate of different surface roughness, however, influences the tensile or flexural strength and the compressive strength in the same manner, maintaining a direct proportionality between flexural strength and compressive strength.

The final fracture of concrete in compression with or without lateral pressure is by shear localization. Because of the uniformly porous and cracked initial state of concrete, however, it is common that a single specimen develops more than one localization nucleus, resulting in multiple shear planes and fragmentation during the final instability. In view of this, the final fracture process often is referred to as crushing in the concrete literature.

\section{Inelastic Behavior of Concrete}

The early onset of microcracking in concrete gives the material considerable apparent inelastic behavior with apparent work hardening that is of considerable concern and importance in structural engineering applications relying on the use of reinforced concrete. As a result, the subject has been researched phenomenologically in considerable detail. The phenomenological models for this inelastic behavior of concrete, developed after the style of the phenomenological theories of plasticity using the invariants of the stress tensor, were discussed. in chapter 3 . The subject has been treated extensively for many years with studies ranging in 


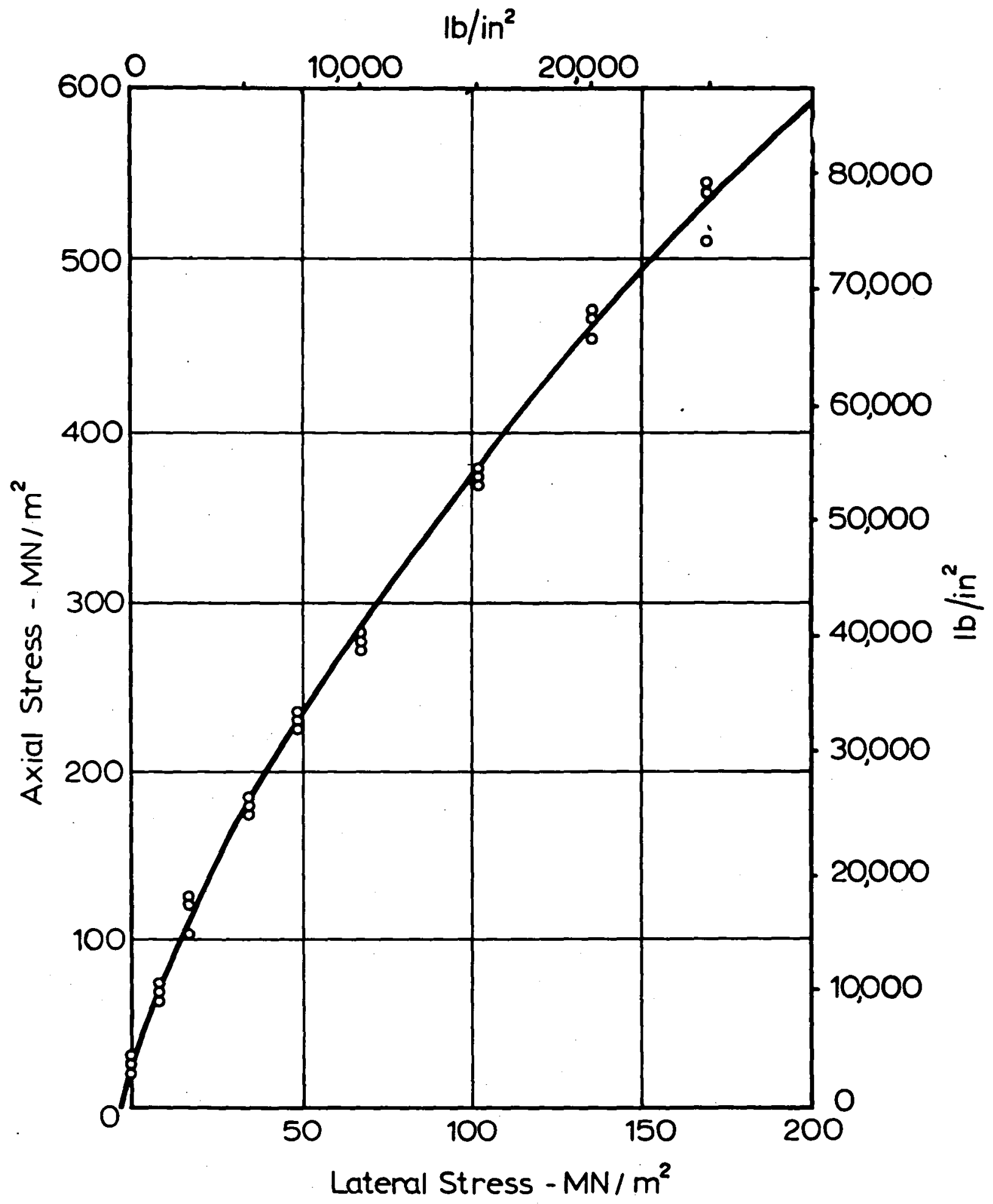

FIGUKE 15 Increase of compressive strength of a typical concrete with lateral stress; a similar behavior exists for neat cement and mortar as we11, indicating that the strength-limiting weak interfaces are not just a result of aggregates (Neville 1975). 


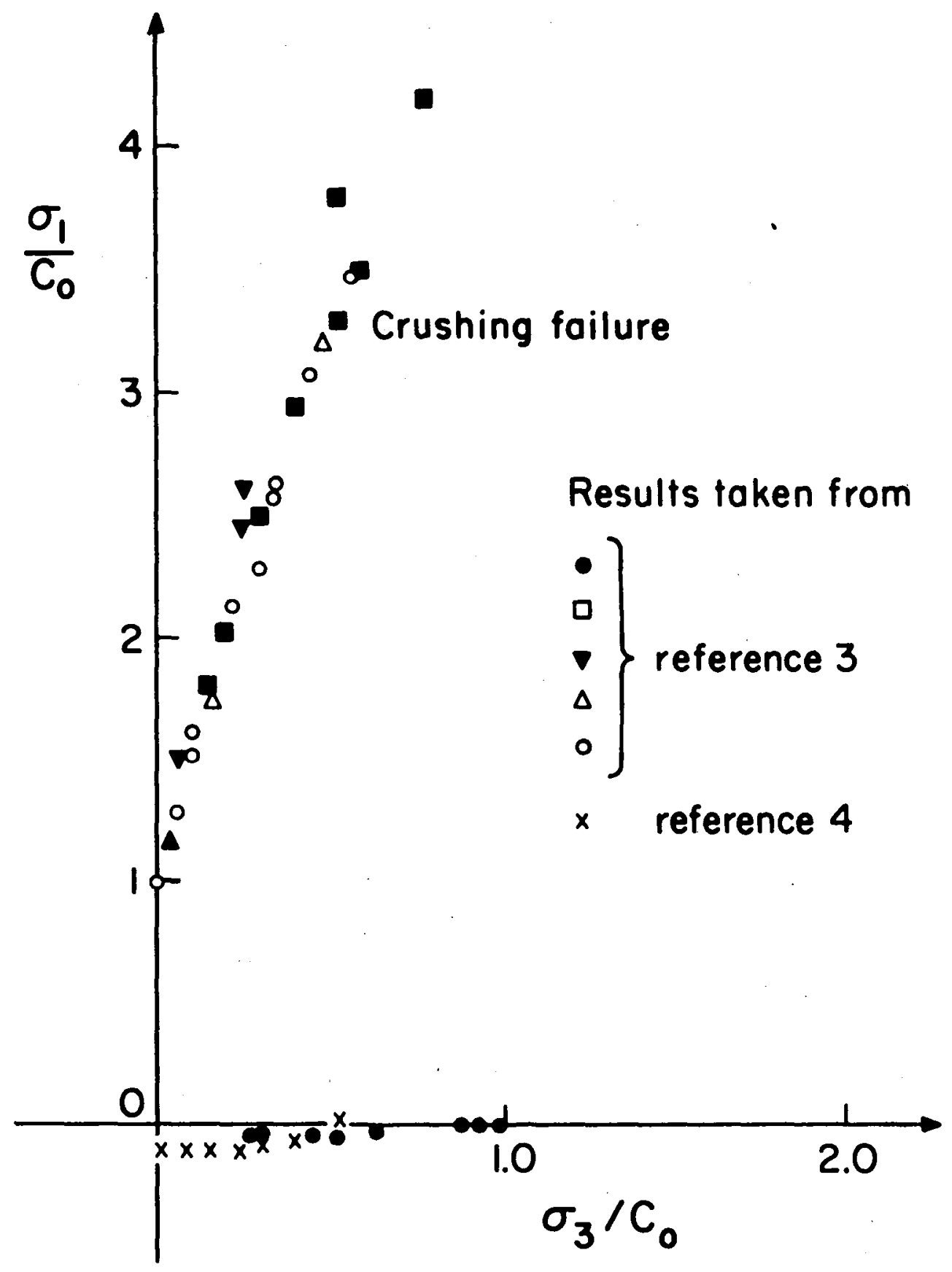

FIGURE 16 Increase of compressive strength $\sigma_{1}$ of concrete with confining pressure $\sigma_{3}$, both normalized with the uniaxial compressive strength $\mathrm{C}_{0}$ without confining pressure (Lowe 1979). 
sophistication from the use of the Coulomb-Mohr criterion to those involving the development of concepts of pressure-dependent plastic resistance and dilatancy. Some of these developments have been summarized by Hsieh and co-workers (1980). Current civil engineering practice for dealing with the apparent plasticity of concrete is described in detail by Chen (1982).

In most instances the current practice, which is based on fitting the observed inelastic behavior by parameterized forms of pressure-dependent yield surfaces, gives adequate and useful results but provides only minimal fundamental understanding. In this sense there is a parallel to the situation existing between the formal mathematical theory of plasticity and the mechanistic theory of crystal plasticity for plastic flow and strain hardening based on dislocation interactions. In reality, however, the situation in concrete must be far simpler. Although the inelastic strains in concrete are produced by the shearing of interfaces and the opening up of microcracks that generally are equivalent to the introduction of generalized dislocation dipoles, there is no long range motion of these dislocations and the topology is uncomplicated. Furthermore, the hardening is a result of exhaustion of weak sites for microcracking, not of mutual blocking of extending microcracks. The termination of inelastic behavior by shear faulting in concrete can be modeled by the modified biaxial fracture theory of Griffith as a linearized scaling law on the basis of the close parallel between Figures 16 and 7 . As these figures show, however, the actual fracture strength in compression rises less than linearly with confining pressure. Furthermore, as discussed earlier, the theory of McClintock and Walsh (1962) is based on microcrack extension while the terminal instability is a result of en echelon activity of adjacent microcracks. The theoretical model of Rudnicki and Rice (1975) that treats the faulting as a constitutive bifurcation problem, even though mechanistically more appealing, is not well enough developed for operational use in practice.

\section{FRACTURE IN CEMENTED CARBIDES}

Cemented carbides, (e.g., tungsten carbide) bound together with a ductile matrix of cobalt are typical, highly filled, hard, cutting tool materials with very low ductility in tension but good strength in compression.

Although they might be expected to be ideal as model materials for studying the shear-faulting fracture in compression in metal matrix materials, there have been very few investigations into this subject. In one of the few isolated st.udies of the compressive strength of cemented carbides, Lueth and Hale (1970) tested $1 \mathrm{~cm}$ diameter cylinders of $2.5 \mathrm{~cm}$ length in simple compression and observed them to fail along a conical surface emanating from the periphery of the contact area with the compression platens. These investigators explained their results as having axisen from the higher peripheral contact pressure that is produced when the contact surface friction prevents the demanded radial expansion at the contact surface while the center plane of the cylinder expands laterally. The final fracture was along the surface of a cone with a 33 degree apex half angle along which the shear stresses were largest. A parallel microscopy study indicated that the fracture progressed entirely through the ductile binder phase of cobalt. Since cobalt does not undergo cleavage fracture, the similarity between this failure phenomenon and the shear faulting process in brittle solids (e.g., 
rock or concrete) is only in a generalized sense where plastic shear flow in the thin ductile phase must be impeded by the eventually blocking action of the tungsten carbide filler and proceed only by widespread interface cavitation resulting in dilatancy.

In another more general study Takagi and Shaw (1982) have carried out tension and compression experiments on a number of brittle solids including cemented carbides. Their results differ from most others that are published and can be understood only if the flaws giving rise to fracture were considered to be spherical cavities instead of cracks with large aspect ratio.

Further study of fracture in cemented carbides, both phenomenologically and mechanistically, may be quite useful in developing a better understanding of the corresponding phenomenon in ultra-high-strength steel.

\section{FRACTURE IN HIGH STRENGTH METALS}

There are few, if any, well documented reports of fracture in compression of high-strength metals. The shear localization studies of Anand and Spitzig (1980 and 1982), to which reference was made in chapter 4, have established, for example, that in high strength maraging steel deformation readily localizes into shear bands in compressive loading governed by the pressure-dependent and dilatant plastic flow. If the dilatancy is due to ductile cavity initiation, fracture can follow along the surfaces of localization. Thus, such compressive failures, albeit of a ductile nature, have the same features as those in brittle rock or concrete and obey very similar stress conditions. Clearly, additional investigations on this mode of fracture are in order. 
COMPRESSIVE FRACTURE IN COMPOSITES

Fiber composites are designed primarily to be used in tensile load-bearing structures where optimum performance requires careful alignment of fibers in the direction of principal tension. Many such structural members, however, also are subjected occasionally to compressive loading where failure can involve buckling of the component or compressive failure in the composite microstructure itself.

The behavior of fiber composites exposed to axial compressive loading has been explored in a limited set of experimental studies (Chaplin 1977, Weaver and Williams 1975, Evans and Adler 1978). These studies, performed respectively on glass/epoxy, carbon/epoxy, and carbon/carbon composites, have revealed a common damage mechanism--the formation of kinks in fiber bundles, inclined to the fiber axis (Figure 17). This kinking behavior is akin to that observed by Orowan (1942) during the compressive testing of single crystals of hexagonal metals. The kinking in fiber composites is accompanied by fiber fracture at the kink boundaries (Evans and Adler 1978). Kinking should thus be regarded as a damage mechanism that both limits the compressive load-bearing capacity of the composite and substantially enhances the failure susceptibility in the presence of a subsequent tensile load.

Initial analysis of the kinking phenomenon by Rosen (1970) was based on the premise that failure occurred by elastic buckling of the fibers in an elastic matrix of higher compliance. This elastic shear buckling analysis anticipates an inclination of the plane of the kink to range between 20 and 50 degrees, depending on the kink width. Comparison of the predicted buckling stresses, based on the Rosen theory, with compressive strengths measured on glass/epoxy and carbon/epoxy systems reveals a substantial discrepancy with the measured strengths being appreciably less than the buckling stress, even on well aligned systems. The discrepancy is undoubtedly associated with the presence of imperfections such as initial fiber curvature, interface voids, and fiber misalignment. 


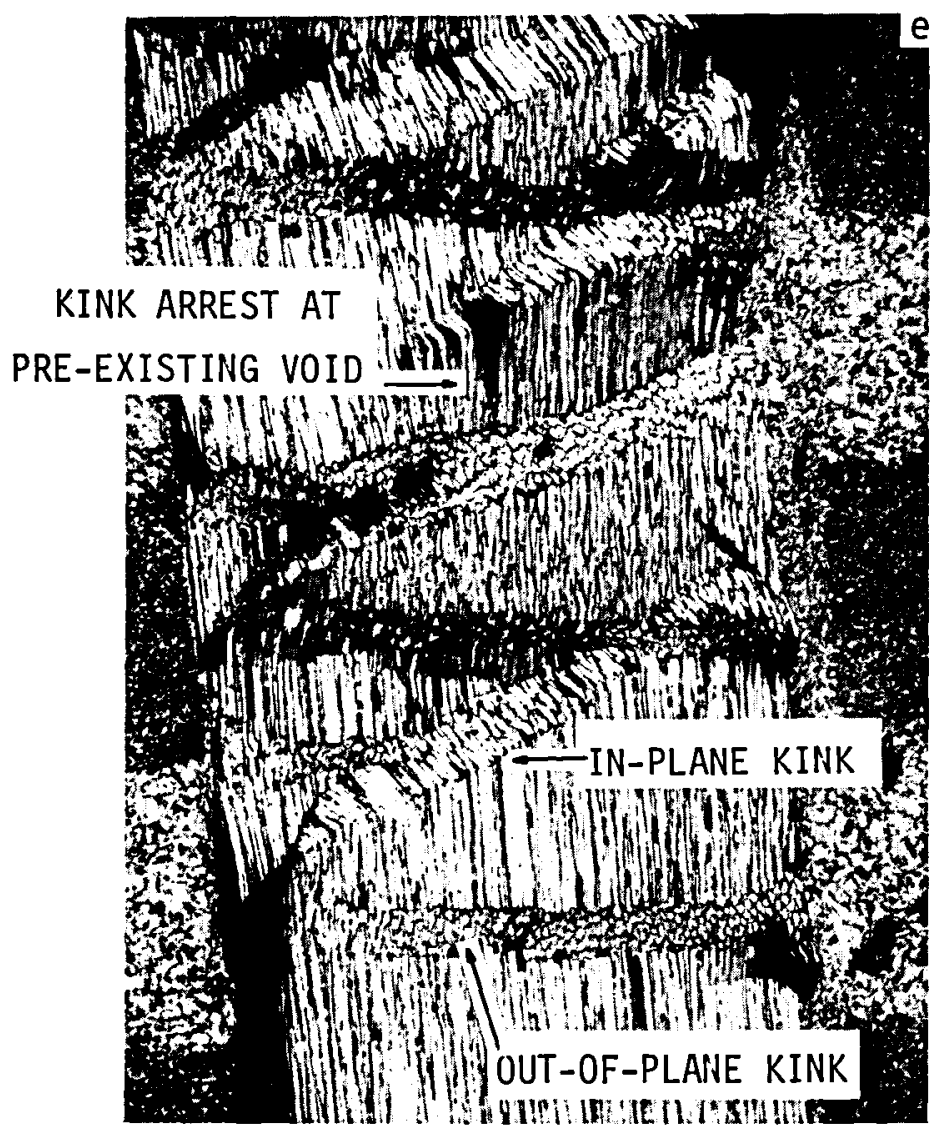

FIGURE 17 Examples of failure in compression by fiber kinking in a carbon fiber composite (Evans and Adler 1978).

The imperfection sensitivity is relatively minor in elastic buckling situations and cannot account for the discrepancy. However, recognition of the relatively large matrix shear stresses involved in the kinking process suggests that imperfection-induced inelastic buckling is a more plausible mode of compressive failure. An approximate theory (Argon 1972, Budiansky 1983) shows readily that the compressive strength of the composite is directly proportional to the shear strength of the plastic matrix and inversely proportional to the angle of misalignment between the fibers and the axis of compression. A substantial influence of the initial misorientation is evident with this mode of kinking. Specifically, initial fiber rotations of less than 3 degrees predict critical kinking stresses comparable to the compressive strengths measured on composite systems. Misorientations of this magnitude are commonly encountered in fiber composites. It may reasonably be concluded, therefore, that elastic/plastic kinking in the presence of small fiber imperfections, manifested as initial fiber rotations or misalignment, is the predominant source of compressive weakness in fiber composites.

The specific kink inclinations exhibited in composites, although incidental to the analysis and interpretation of the compressive strength, 
also require rationalization. The observed relation between the angle of shear inside the kink and the angle of kink inclination is simply rationalized by the requirement that zero axial strain must be maintained within the kink. However, the specific magnitude of each angle does not emerge from the simple instability analyses used to predict the critical stress. Nevertheless, a prediction of the kink angle and the kink width can be obtained by considering the bending of the fibers within the vicinity of the initial imperfections and analyzing the ensuing fiber fracture. Fiber bending generates stresses that depend on both the width and amplitude of the bend zone. Hence, by associating the width of the bend zone with the kink width and by allowing fiber fracture to occur at a critical tensile strain, a kink width can be computed which is in tolerable agreement with experimental observations (Budiansky 1983).

The preceding description of kinking permits the conclusion that the resistance of fiber composites to compressive failure is contingent primarily on the plastic flow characteristics of the matrix and on local fiber misalignment. The mechanical properties of the fiber only influence the resultant kink geometry. Recognizing that the strong sensitivity of the failure stress to small initial fiber rotations excludes improved fiber alignment as a technologically feasible approach to compressive strength enhancement, the only viable materials design approach available is to raise the plastic flow resistance of the matrix. However, it should be appreciated that such modifications may degrade the tensile properties of the composite.

The important influence of small fiber imperfections also excludes nondestructive evaluation as a viable technique for the identification of deficient components with large fiber misalignment. For example, ultrasonic methods would not be capable of detecting such misalignments because, at the high frequencies needed to achieve the necessary resolution, the material attenuation would be excessive. 
NONDESTRUCTIVE EVALUATION

\section{INTRODUCTION}

In chapter 2 two separate classifications of fracture behavior in compression were identified: extrinsic behavior resulting from pre-existing macro flaws having the character of shear cracks that can extend in a sigmoidal manner and split the sample parallel to the maximum principal direction of compression and intrinsic behavior resulting from the interaction of small stable microcracks, en echelon, leading to the formation of a shear fault. The evolution of intrinsic behavior could be advanced, in principal, by the presence of a suitable shear fault nucleus that can grow more rapidly under suitable conditions. Thus, the suppression or control of such fractures suggests the detection of flaws by nondestructive evaluation techniques to either predict the behavior or monitor the evolution of the failure process.

For intrinsic behavior, the failure process starts with development of stable microcracks from microstructural flaws such as weak interfaces, grain boundaries, and misaligned reinforcing elements in composites. These are either abundant in number or very hard to distinguish from the background at the start when the interfaces are likely to be largely intact. Unce the part is deformed and microcrack extension begins, the process could be monitored readily by acoustic emission directly in an active mode or by acoustic backscattering in a passive mode. Thus, for intrinsic behavior, although the initial state of a previously unstressed sample is difficult to characterize in a discriminating manner, subsequent stages of microcracking or the detection of microcracks in a previously stressed sample is readily achievable.

For extrinsic behavior, the sample must contain a large discontinuity of the order of the sample dimensions. The detection of such a large crack-like flaw should be possible with any of a large number of nondestructive evaluation or inspection techniques. 


\section{ACOUSTIC PROBING TECHNIQUES}

\section{Acoustic Emission}

$\mathrm{AE}$ is the most widely used nondestructive method for microstructural assessment in compressively loaded brittle materials and for actively monitoring the evolution of damage by recording and analyzing the sound emitted from the sources of failure. An $\mathrm{AE}$ signal is an elastic wave generated as a result of a sudden relaxation of stress in a portion of the material by a local failure process. The acoustic emissions are in the form of more or less sharply defined discrete pulses that may have a broad frequency range from very low values up to several MHz. The application of $\mathrm{AE}$ t.o the study of clustering of damage en echelon in compressively stressed rock is described in chapter 4.

\section{Acoustic Backscattering}

The passive evaluation of damage in previously stressed samples can be done by acoustic backscattering, in the long wavelength regime, where the wavelength should be no smaller than at least 5 times the grain diameter or principal microstructural dimension of the sample. At such long wavelengths, the attenuation due to grain or microstructure scattering should be acceptably small (Evans et al. 1978) while substantial scattering should occur from individual microcracks (Kino 1978). The scattering amplitude, A, from discrete microcracks of dimension, a, varies as the cube of a. The large extreme of the microcrack distribution is thus readily detectable. In general, individual, large microcracks are detected if separated from neighboring cracks by a distance greater than the acoustic wavelength; otherwise, a measure of the cumulative microcrack damage, within a local region of the material, is obtained. Specifically, since acoustic scattering relates to the mismatch in acoustic impedance between the damaged and undamaged region, the scattering amplitude from a damage zone is dictated primarily by the reduced elastic moduli associated with the microcracking. The density changes are important only if appreciable local dilatation occurs. The elastic modulus reduction is dictated by the product of the number density of microcracks and the average scattering amplitude of a typical microcrack (Budiansky and $0^{\prime}$ Connell 1976). Hence, regions containing a relatively high density of large microcracks yield large scattering amplitudes.

Inversion procedures can be used to relate the detected scattering amplitude to the dimensions of the damage zone and the damage intensity. Both time domain (Chou et al. 1980) and frequency domain (Richardson and Evans 1980) information can be used to develop interpretive procedures pertinent to microcrack damage. Good spatial resolution, suitable for the precise location of the damage zone, may be achieved using focused transducers. The acoustic backscattering technique thus has the basic versatility and sensitivity needed to obtain detailed information concerning damage accumulation under compressive loading conditions. 
OTHEK NDE TECHNIQUES

Large crack-like flaws resulting in extrinsic behavior can be detected by a large number of nondestructive evaluation techniques. Some of these techniques work best for surface defects whereas others are capable of discriminating flaws both on the surface and in the interior of a sample. These techniques are well known and widely used. Hence, only a listing of these techniques will be presented here: ultrasonic testing, radiography, eddy current testing (near-surface flaws), liquid penetrant testing (surface flaws only), and magnetic testing.

\section{FLAW DETECTION SENSITIVITY AND RELIABILITY}

Flaw detection sensitivity is governed by the physical limitations of the method involved whereas flaw detection reliability, the probability of detection of an existing flaw, also is limited by the proficiency of the operator. In current engineering practice flaws less than $3 \mathrm{~mm}$ in length usually are not reliably detectable. In a comprehensive reliability study of nondestructive testing, as practiced by the U.S. Air Force maintenance inspectors, Lewis and co-workers (1978) found that there was considerable difficulty in demonstrating a 50 percent probability of detecting a $13 \mathrm{~mm}$ crack with 95 percent confidence limits in simulated field tests of airframe structures. On this basis it can be concluded that in normal practice a 3 mm long flaw represents the smallest detectable size while a $13 \mathrm{~mm}$ long crack is probably a more realistic limit in routine inspection under field conditions.

As discussed in chapter 7 , active inspection techniques using $A E$ can detect activity from flaws of much smaller size provided that the signal has sufficient intensity and the location need not be traced too precisely. Similarly, the presence of individual microcracks or clouds of microcracks of dimensions several times that of a grain size can be detected by acoustic backscattering.

\section{REFERENCES}

Altiero, N. J. and D. L. Sikarskie. 1974. Mech. Res. Comm. 1:225. Anand, L. 1980. J. of App 1. Mech. 47:439. Anand, L. 1982. J. Mech. Phys. Solids. In press.

Anand, L., and W. A. Spitzig. 1980. J. Mech. Phys. Solids 28:113. Anand, L., and W. A. Spitzig. 1982. Acta Metallurgica 30:553.

Argon, A. S. 1972. Treatise on Materials Science and Technology, p. 79. H. Herman, ed. New York: Academic Press.

Argon, A. S. 1980. Glass: Science and Technology, p. 79. D. R. Uhlmann and N. J. Kreide, eds. New York: Academic Press.

Arțhur, J. R. F., T. Dunstan, Q. A. J. L. Al-Ani, and A. Asani. 1977. Geotechnique 27:53.

Atkinson, B. K. 1979. Compilation of Experimentally Determined Fracture Mechanics Parameters for Geological Materials. Final Technical Report to U.S. National Earthquake Hazards Reduction Program. London: Imperial College of Science and Technology of the University of London. 
Atkinson, B. K. 1982. J. Struct. Geology 4:41.

Bailey, C. D., J. M. Hamilton, Jr., and W. M. Pless. 1979. Mater. Eval. $37(6): 43$.

Batzle, M., G. Simmons, and R. W. Siegfried. 1980. J. Geophys. Res. $85: 7072$.

Bazant, Z. P., and S. S. Kim. 1979. J. Eng. Mech. Div. of ASCE 105:407.

Bazant, 2. P., and T. Tsubaki. 1980. J. Eng. Mech. Div. of ASCE 106:1151.

Benjumea, R., and D. L. Sikarskie. 1969. Int. J. Rock Mech. Min. Sci. $6: 343$.

Bieniawski, Z. T., and W. L. van Heerden. 1975. Int. J. Rock Mech. Min. Sci. 12:101.

Biot, M. A. 1941. J. Appl. Phys. 12:155.

Bonner, B. P. 1974. Geophys. Res. Lett. 1:217.

Brace, W. F. 1978. PAGEOPH 116:603.

Brace, W. F. 1981. Geophys. Res. Lett. 8:651.

Brace, W. F., and E. G. Bombolakis. 1963. J. Geophys. Res. 68:3709.

Brace, W. F., and R. J. Martin III. 1968. Int. J. Rock Mech. Min. Sci. $5: 415$.

Brace, W. F., and A. S. Orange. 1968. J. Geophys. Res. 73:1433.

Brace, W. F., B. Paulding, and C. H. Scholz. 1966. J. Geophys. Kes. $71: 3939$.

Brace, W. F., E. Silver, K. Hadley, and C. Goetze. 1972. Science 178:163.

Brace, W. F., and J. B. Walsh. 1962. Amer. Min. 47:1111.

Budiansky, B. 1983. Computers and Structures 16(1-4):3

Budiansky, B., and J. O'Conne11. 1976. Int. J. Solids Struct. 12:81.

Byerlee, J. D., and D. Lockner. 1977. Proceedings of the First Conference on Acoustic Emission/Microseismic Activity in Geological Structures and Materials, p. 87. H. R. Handy Jr. and F. W. Leighton, eds. Clausthal, FRG: Trans Tech.

Chaplin, C. R. 1977. J. Mater. Sci. 12:347.

Cheatham, J. B., and D. L. Sikarskie. 1973. Rock Mechanics Symposium, D.L. Sikarskie ed., AMD-Vol. 3, p. 41. New York: American Society of Mechanical Engineers.

Chen, W. F. 1982. Plasticity in Reinforced Concrete. New York: McGraw-Hill.

Chou, C. H., B. T. Khuri-Yakub, G. S. Kino, and A. G. Evans. $1980 . \mathrm{J}$. Nondestruct. Eva1. 1:235.

Drescher, A., K. Kwaszczynska, and 2. Mroz. 1967. Archiwum Mechaniki Stosowanej 19:99.

Drucker, D. C. and W. Prager. 1952. Q. App 1. Math 10:157.

Erdogan, F., and G. S. Sih. 1963. Trans. ASME J. Basic Eng. 85D:519.

Evans, A. G., and W. F. Adler. 1978. Acta Metallurgica 26:725.

Evans, A. G., L. Ahlberg, B. R. Tittmann, B. T. Khuri-Yakub, and G. S. Kino. 1978. J. Appl. Phys. 49:2669.

Evans, I., and S. A. F. Murre11. 1958. Mechanical Properties of Nonmetallic Brittle Materials, p. 432. W. H. Walton, ed. New York: Interscience.

Frank, F. C. and A. N. Stroh. 1952. Proc. Phys. Soc. B65:811. Friedman, M., J. Handin, N. G. Higgs, and J. R. Lantz. 1979. Proceedings of the 20th Symposium on Rock Mechanics, p. 35. Austin: University of Texas, Center for Earth Sciences and Engineering.

Gerstle, K. H. et al. 1980. J. Eng. Mech. Div. of ASCE 106:1383. 
Goodman, R. E. 1980. Introduction to Rock Mechanics, p. 475. New York: J. Wiley and Sons.

Graham, L. J. and G. A. Alers. 1974. Mater. Eval. 32(2):31.

Griffith, A. A. 1920. Phil. Trans. Roy. Soc. A221:163.

Griffith, A. A. 1924. Proceedings of the lst International Conference on Applied Mechanics, p. 55. Delft, Holland: Technische Boekhandel en Drukkerij J. Walt ham Jr.

Hadley, K. 1976. J. Geophys. Res. 81:3484.

Handin, J., D. V. Higgs, and J. K. O'Brien. 1960. Rock deformation, p. 245. GSA Memoir No. 79. D. Griggs and J. Handin, eds. Boulder, Colorado: Geological Society of America.

Handin, J., K. V. Hager, M. Friedman, and J. N. Feather. 1963. Bulletin Amer. Assoc. Petro1. Geol. 47:717.

Handin, J., H. C. Heard, and J. N. Magouirk. 1967. J. Geophys. Res. 72:611. Harris, T. A. 1966. Rolling Bearing Analysis. New York: John Wiley and Sons.

Hartman, H. L. 1959. AIME Trans. 24:68.

Hoek, E., and Z. T. Bieniawski. 1966. Fracture Propagation Mechanism in Hard Rock. Proceedings of the First Congress Intern. Society of Rock Mechanics, Vol. 1, p. 243. Lisbon: Laboratorio Nacional de Engenharia Civil.

Hoek, E., and E. T. Brown. 1980. Underground Excavations in Rock, p. 138. London: Inst. Min. Metal.

Hodgson, K., and N. G. W. Cook. 1970. Proceedings of the 2nd Congr. Int. Soc. Rock Mech., vol. 2, p. 31. Belgrade: Institut za Vodoprivredu "Jaroslav Cerni."

Hsieh, S. S., E. C. Ting, and W. F. Chen. 1980. Fracture in Concrete, p. 50. W. F. Chen and E. C. Ting, eds.. New York: American Society of Civil Engineers.

Hutchinson, J. W., and V. Tvergaard. 1981. Int. J. Solids Structures $17: 451$.

Irwin, G. R. 1957. J. App1. Mech. 24:361.

Jaeger, J. C., and N. G. W. Cook. 1979. Fundamentals of Rock Mechanics. New York: Halsted Press.

Kachanov, M. L. 1982. Mech. Mater. 1:19.

Kino, G. S. 1978. J. Appl. Phys. 49:3190.

Kranz, R. L. 1979. Int. J. Rock Mech. Min. Sci. 16:23.

Kranz, R. L. 1980. J. Geophy 8. Res. 85:1854.

Kranz, R. L., W. J. Harns, and N. L. Carter. 1982. Geophys. Res. Lett. 9:1. Kupfer, H. B. and K. H. Gerstle. 1973. J. Eng. Mech. Div. of ASCE 99:853.

Lewis, W. H., W. H. Sprout, B. D. Dodd, and J. M. Hamilton. 1978. Reliability of Nondestructive Inspections. Final Keport SA-ALC/MME 76-6-38-1. Kelly AFB, Texas: Department of the Air Force.

Lockner, D. A., J. B. Walsh, and J. D. Byerlee. 1977. J. Geophys. Res. $82: 5374$.

Lockner, D. A. and J. D. Byerlee. 1980. Proceedings of the 2nd Conference on Acoustic Emission/Microseismic Activity in Geological Structures and Materials, p. 11. H. K. Handy Jr. and F. W. Leighton, eds. Clausthal, FKG: Trans. Tech.

Lowe, P. G. 1979. Mag. of Concrete Res. 30:200.

Lueth, R. C. and T. E. Hale. 1970. ASTM Mater. Res. and Stand. $10: 23$. 
McClintock, F. A. 1965. Proc. Roy. Soc. A285:58.

McClintock, F. A. and J. B. Walsh. 1962. Proceedings of the 4th U. S. National Congress of Applied Mechanics 2:1015.

McClintock, F. A. and H. J. Mayson. 1976. The Effects of Voids on Materials Deformation, AMD-vo1. 16, p. 31. C. S. Cowin and

M. M. Carro11, eds.. New York: American Society of Mechanical Engineers.

McLamore, R. T. 1971. J. Petrol. Tech. 23:1313.

Mizutani, H., H. Spetzler, I. Getting, R. J. Martin III, and N. Soga.

1977. Proceedings of the 8th Lunar Science Conference, p. 1235.

New York: Pergamon Press.

Mogi, K. 1968. Bu11. Earthquake Res. Inst. 46:1103.

Mogi, K. 1972a. Phys. Earth Planet. Int. 5:318.

Mogi, K. 1972b. The upper mantle. Tectonophysics 13(1-4):541.

Mogi, K. 1978. Earthquake precursors. Proceedings of the United States-Japan Seminar on Theoretical and Experimental Investigation of Earthquake Precursors, p. 203. C. Kisslinger and Z. Suzuki, eds. Tokyo: Center for Academic Publications.

Mroz, Z. and Cz. Szymanski. 1979. Limit Analysis and Rheological Approach in Soil Mechanics, p. 50. W. Olszak and L. Suklje, eds. Vienna, New York: Springer.

Mugge, 0. 1898. Neues Jahrb. Miner. 1:71.

National Research Council. 1980. The Status of Cement and Concrete R\&D in the United States. Report NMAB-361. Washington, D.C.: National Academy Press.

National Research Council. 1981. Rock-Mechanics Research Requirements for Resource Recovery, Construction, and Earthquake-Hazard Reduction, p. 1-222. Panel on Rock-Mechanics Research Requirements of the U.S. National Committee on Rock Mechanics. Washington, D.C.: National Academy Press.

National Science Foundation. 1981. Berkeley workshop on large-scale laboratory testing in geomechanics. Geophys. Res. Lett. 8:645.

Nemat-Nasser, S. and A. Shokooh. 1980. Int. J. Solids Struct. 16:495. Nemat-Nasser, S. and H. Horii. 1982. J. Geophys. Res. 87:6805.

Neville, A. M. 1975. Properties of Concrete. New York: Wiley \& Sons.

Ohnaka, M. 1973. J. Phys. Earth 21:125.

Orowan, E. 1942. Nature 149:643.

Paterson, M. S. 1978. Experimental Rock Deformation-The Brittle Field. Vienna, New York: Springer.

Pau1, B. and D. L. Sikarskie. 1965. Trans. AIME 232:372.

Pratt, H. R., A. D. Black, W. S. Brown, and W. F. Brace. 1972. Int. J. Rock Mech. Min. Sci. 9:513.

Reichmuth, D. R. 1963. Rock Mechanics, p. 33. C. Fairhurst, ed. Oxford: Pergamon Press.

Rice, J. R., and M. P. Cleary. 1976. Rev. Geophys. Space Phys. 14:227.

Richardson, J. M., and A. G. Evans. 1980. J. Nondestruct. Eval. 1:37.

Richter, D., and G. Simmons. 1977. The earth's crust, p. 149. AGU Monograph 20:149.

Rosen, B. W. 1970. Mechanics of Composite Materials, p. 621. F. W. Wendt, H. Liebowitz, and N. Perone, eds. Oxford: Pergamon Press. 
Kothman, K. L. 1977. Proceedings of the 1st Conference on Acoustic Emission/Microseismic Activity in Geological Structures and Materials, p. 109. H. R. Handy Ji. and F. W. Leighton, eds. Clausthal, FRG: Trans. Tech.

Rudnicki, J. W. 1977. Proceedings of the 18th United States Symposium on Rock Mechanics, p. 3B4-1. Colorado School of Mines: Johnson Publishing Company.

Kudnicki, J. W., and J. R. Kice. 1975. J. Mech. Phys. Solids 23:371. Kutter, E. H. 1972. Techtonophysics 14:13.

Scholz, C. H. 1968a. Bull. Seism. Soc. Amer. 58:399.

Scholz, C. H. 1968b. J. Geophys. Res. 73:1447.

Scholz, C. H. 1968c. J. Geophys. Res. 73:3295.

Scholz, C. H. 1968d. J. Geophys. Res. 73:1417.

Sih, G. S. 1973: Mechanics of Fracture 1, Methods of Analysis and Solutions of Crack Problems, p. XXI. G. S. Sih, ed. Leyden: Noordhoff. Sikarskie, D. L. 1966. Experiments on Wedge Indentation in Rocks. Report TN-262. Princeton, N.J.: Ingersol Rand Research and Development Cent.er.

Sikarskie, D. L., and N. J. Altiero. 1973. J. App1. Mech. 40:791. Singh, M. M., and A. M. Johnson. 1967. Trans. AIME 38:366. Singh, M. M., and P. J. Huck. 1973. Proceedings of the 14th United States Symposium on Rock Mechanics, p. 35. H. R. Handy and R. Stefanko, eds. New York: American Society of Civil Engineers.

Soga, N., H. Mizutani, H. Spetzler, R. J. Martin III. 1978. The effect of dilatancy on velocity anisotropy in westerly granite. J. Geophys. Res. $83: 4451-4458$.

Sondergeld, C. H. and L. H. Estey. 1981. J. Geophys. Res. 86:2915. Sondergeld, C. H. and L. H. Estey. 1982. PAGEOPH 120:151-66. Spencer, A. J. M. 1982. Mechanics of Solids, p. 607. H. G. Hopkins and M. J. Sewe11, eds. Oxford: Pergamon Press.

Sprunt, E. S. and W. F. Brace. 1974. Int. J. Rock Mech. Min. Sci. 11:139. Szczepinski, W. 1971. Archiwum Mechaniki Stosowanej 23:885.

Tada, H., P. C. Paris, and G. R. Irwin. 1972. The Stress Analysis of Cracks Handbook. Hellertown, Pennsylvania: Del Research Corporation.

Takagi, J., and M. C. Shaw. 1982. Brittle Fracture Initiation Under Complex Stress States. Report $\mathrm{CR}-\mathrm{R}-82016$. Tempe: Arizona State University College of Engineering and Applied Sciences.

Tapponier, P., and W. F. Brace. 1976. Int. J. Rock Mech. Min. Sci. 13:103. von Karman, T. 1911. Druck. Z. Verein. Deutch. Ing. 55:1789.

Weaver, C. W. and J. G. Williams. 1975. J. Mater. Sci. 10:1323.

Weibul1, W. 1939. Ing. Vetenskaps Akad. Proceedings (Handlingar) No. 151. Whittaker, B. N., and A. B. Szwilskie. 1973. Int. J. Rock Mech. Min. Sci. $10: 659$.

Wong, T. F. 1982a. Mech. Mat1s. $1: 3$.

Wong, T. F. 1982b. Int. J. Rock Mech. Min. Sci. 19:49.

Wong, T. F. 1982c. J. Geophys Res. 87:990.

Zoback, M. D., and J. D. Byerlee. 1975. J. Geophys. Res. 80:752. 

Curricula Vitae

ALI S. ARGON received his bachelors degree from Purdue Univèrsity and his advanced degrees from Massachusetts Institute of Technology. He taught at a university in Turkey before joining the MIT faculty in 1960. His teaching and research have been in the field of mechanics and behavior of engineering materials. In 1976 he received the Charles Russ Richards award from the ASME.

AMOS A. BRADD has had varied metallurgical experience, although his degree from CCNY was in chemical engineering. From 1946-1949 and 1951-1976. he was with the Midvale Company as roll engineer. He has taught at Temple University and wrote chapters for "Basic Metallurgy," published by the American Society for Metals. A fellow of ASM, he was chairman of the Philadelphia Chapter in 1962 and the Philadelphia Section of AIME in 1949.

JOHN D. EMBURY, a native of England, was educated at Manchester and Cambridge Universities. His industrial experience was with U.S. Steel. He has taught at Newcastle University and at McMaster University, where he is now Professor of Metallurgy and Materials Science. His professional interest has been largely in the area of deformation and fracture.

ANTHONY G. EVANS also received his training in England, at the University of London. He has worked with ceramics at Harwell and, in this country, at the National Bureau of Standards and the Rockwell Science Center before becoming a professor at the University of California in Berkeley in 1978. He has been a leader in developing an understanding of the mechanical behavior of brittle materials.

JOHN W. HUTCHINSON, a graduate of Lehigh and Harvard Universities, has taught at Harvard University since graduation in 1963. His visits and sabbaticals have been spent at the Technical University of Denmark and Oxford and Cambridge Universities. In line with his interest in flow and fracture, he heads the ASTM Subcommittee on Advanced Concepts in Fracture Mechanics of Committee E24.

WILLIAM H. LEWIS, JR. is the Manager of Engineering Technical Services for the Lockheed-Georgia Company. He joined Lockheed upon graduating from Virginia Polytechnic Institute with a degree in metallurgical engineering. Except for three years in the Air Force, he has been with Lockheed since 1956, specializing in nondestructive testing. A fellow of ASNT, he was chairman of their Technical Council and a national director, and past president of local sections of ASM and ASNT.

DAVID SIKARSKIE earned degrees from the University of Pennsylvania and Columbia University in engineering mechanics and civil engineering. After three years with Ingersoll Rand (also Visiting Professor at Princeton 
University), he became Professor of Aeronautical Engineering at the University of Michigan. Since 1979 he has been Professor and Chairman of the Department of Metallurgy, Mechanics, and Materials Science at the Michigan State University in East Lansing. He received the Tau Beta Pi Outstanding Teacher award in 1973, and is a NDEA Fellow.

TENG-FONG WONG graduated from Brown University with a BS in applied mathematics, Harvard with an MS in Applied Mechanics, and,MIT with a PhD in Geophysics. He taught briefly in China, was a research associate at MIT, and is now located in the Department of Earth and Space Sciences at the State University of New York at Stony Brook. 
End of Document 